SFB 649 Discussion Paper 2014-044

$z$
$\underline{\sim}$
$\underline{u}$
$\omega$

\title{
On the Timing of Climate Agreements
}

\author{
Robert C. Schmidt* \\ Roland Strausz*
}

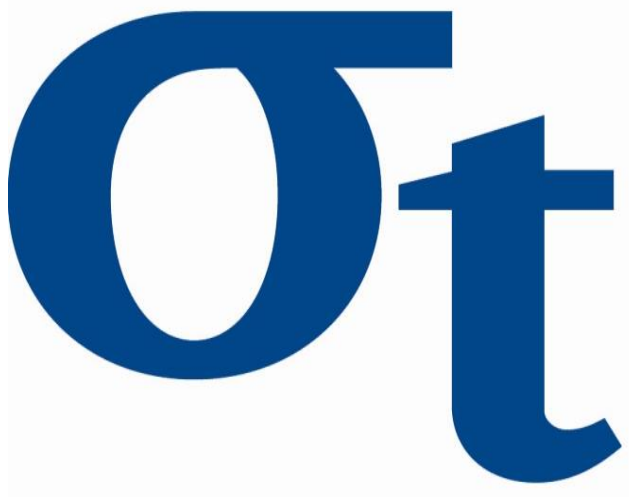

* Humboldt-Universität zu Berlin, Germany

This research was supported by the Deutsche Forschungsgemeinschaft through the SFB 649 "Economic Risk".

http://sfb649.wiwi.hu-berlin.de ISSN 1860-5664 


\title{
On the Timing of Climate Agreements
}

\author{
Robert C. Schmidt* and Roland Strausz ${ }^{\dagger}$
}

July 20, 2014

\begin{abstract}
A central issue in climate policy is the question whether long-term targets for greenhouse gas emissions should be adopted. This paper analyzes strategic effects related to the timing of such commitments. Using a two-country model, we identify a redistributive effect that undermines long-term cooperation when countries are asymmetric and side payments are unavailable. The effect enables countries to shift rents strategically via their R\&D efforts under delayed cooperation. In contrast, a complementarity effect stabilizes long-term cooperation, because early commitments in abatement induce countries to invest more in low-carbon technologies, and create additional knowledge spillovers. Contrasting both effects, we endogenize the timing of climate agreements.
\end{abstract}

Keywords: climate treaty, abatement, long-term cooperation, spillover, strategic delay JEL classification: D62, F53, H23, Q55

*Address: Spandauer Str. 1, 10178 Berlin, e-mail: robert.schmidt.1@wiwi.hu-berlin.de

${ }^{\dagger}$ Address: Spandauer Str. 1, 10178 Berlin, e-mail: strauszr@wiwi.hu-berlin.de. We acknowledge financial support by the German Federal Ministry for Education and Research under the CREW-project (FKZ01LA1121C) and Deutsche Forschungsgemeinschaft (SFBTR15, SFB649). We thank the particpants in CREW for many fruitful discussions and suggestions. 


\section{Introduction}

One of the main global challenges of today is the problem of anthropogenic climate change. At its core lies a public goods problem which, by conventional economic wisdom, could be solved by global cooperation that benefits all participants. In practice, global agreements to curb the emission of greenhouse gases have however been proven elusive (e.g., failure of the Copenhagen climate summit, or reluctance of the U.S. to ratify the Kyoto-protocol). Focusing on the timing of climate agreements under multiple externalities, this paper contributes to a growing body of literature that addresses the difficulties in reaching such agreements. ${ }^{1}$ In particular, we consider a dynamic cooperation game, in which countries can either sign a long-term climate agreement before choosing their R\&D investments, delay cooperation until after investing in $\mathrm{R} \& \mathrm{D}$, or decide against cooperation all together. Within this setup we identify the strategic effects of the different options and show how asymmetries between countries and the inability to use side-payments can lead to a delay or even a complete failure of cooperation.

At the heart of our analysis lies the notion that multiple externalities underlie the challenge of climate change. Apart from the environmental externality of emissions, also R\&D efforts in the area of low-carbon technologies exhibit strong externalities globally. In the light of such knowledge spillovers, the development of low-carbon technologies becomes, similar to the abatement of emissions, a global public goods problem itself, which also calls for international cooperation. Yet, in the past, international climate negotiations focused primarily on emissions reductions. We follow this dichotomy and consider countries that can only cooperate in abatement efforts, but not in R\&D.

The double public goods problem of abatement externalities and R\&D spillovers further adds a dynamic aspect to the cooperation problem, because technological progress is a timeconsuming process whereas abatement targets are adjustable also in the near term. To take this dynamic perspective into account explicitly, we model countries' abatement and R\&D choices in two separate stages. In the absence of cooperation, each country chooses first its R\&D efforts, and subsequently its abatement effort.

The timing allows us to distinguish between two types of cooperative outcomes: late and early cooperation. Under 'late cooperation', countries first determine their R\&D efforts noncooperatively, and subsequently choose their abatement efforts cooperatively. Hence, under late cooperation there is a delay in the climate negotiations, and countries' future abatement efforts are determined on a short-term basis after countries have already invested in low-carbon

\footnotetext{
${ }^{1}$ We discuss the relevant literature in the next subsection, where we also relate our results to the existing findings.
} 
technologies. We, however, also consider the possibility that countries sign a long-term contract that fixes future abatement targets early on. Under such 'early cooperation' countries sign an agreement on long-term abatement targets before their R\&D efforts are determined noncooperatively.

Contrasting early to late cooperation, we show that early cooperation is often (NOT ALWAYS?!!) welfare-superior to late cooperation (or no cooperation). The difficulty, however, is to achieve such an early agreement when countries are asymmetric and act strategically. Assuming that side-payments cannot be implemented, a country with a low valuation for climate stabilization may prefer to delay cooperation if it expects a better outcome than under the early agreement. ${ }^{2}$

For each of the two timing regimes, we identify the different strategic effects that arise and show that the relative strength of these effects determine when and whether cooperation obtains in equilibrium. In particular, we identify a redistributive effect that leads to underinvestments in low-carbon technologies under late cooperation. Intuitively, by reducing its own R\&D effort, a country can assure that it is assigned a lower abatement target in the subsequent cooperative stage so that the overall gains from cooperation are shifted in its own favor, even though side-payments are not available. The redistributive effect can, thus, cause a strategic delay of cooperation when countries are asymmetric. We show that even small asymmetries between countries can be sufficient to induce such an inefficient delay of cooperation. Furthermore, we identify a strategic complementarity effect under early cooperation that is related to the double public goods problem. Intuitively, by assigning a higher abatement obligation to a country at the early cooperative stage, the country is induced to invest more in the subsequent non-cooperative R\&D stage when abatement and R\&D are strategic complements. This creates additional knowledge spillovers and, hence, can partially correct for the lack of cooperation in R\&D. The complementarity effect improves the overall welfare under early (long-term) cooperation (as compared to late cooperation), and can stabilize early cooperation even in the presence of large asymmetries between countries.

A necessary requirement for early cooperation to succeed under large asymmetries is the presence of sufficiently strong knowledge spillovers. Furthermore, if the abatement spillovers between countries are asymmetric, then the $R \& D$ spillovers must be asymmetric as well to render early cooperation stable, and they must mainly affect the country that benefits less from

\footnotetext{
${ }^{2}$ We follow the usual modeling approach that whenever countries cooperate, they seek to maximize their joint welfare. Under early cooperation, this implies that they also take into account how their cooperative abatement choices will affect their future, non-cooperative R\&D efforts.
} 
abatement spillovers. To illustrate the potential practical relevance of this, consider a country that attaches a high value to the damages of climate change so that it is strongly affected by the other country's abatement efforts. Suppose further that the other country is a technological follower vis-à-vis the first country, and places a lower weight on the issue of climate change. Under such circumstances a long-term agreement on future abatement efforts may be negotiated successfully, despite the asymmetries between countries. Intuitively, the technological leader is willing to sign an early agreement because it induces the other country to adopt a higher abatement target. Conversely, the technological follower signs the agreement because this induces the leader to subsequently invest more in R\&D. If the resulting technology spillovers are sufficiently strong, they compensate the follower for the higher abatement obligation under an early agreement.

\section{$1.1 \quad$ Related literature}

Although our dynamic model of climate cooperation and the resulting dynamic interplay of the different strategic effects is new, the different strategic effects themselves have already been recognized in the literature. In this subsection we relate our results to both this literature and the broader economic literature on climate cooperation.

The literature that emphasizes the freerider effect as a main obstacle to effective climate cooperation (e.g., Barrett, 1994; Carraro and Siniscalco, 1993, and also Finus 2008) highlights that, since climate stabilization is a public good, each country prefers other countries to abate more, but may not benefit from contributing substantially to this public good itself. As a result of this freerider problem, only a small number of countries may sign a climate treaty, and especially so when the potential gains from cooperation are large. Hence, effective climate treaties that must be self-enforcing with respect to participation, are often not sustainable. Because we analyze cooperation between only two players, we abstract from these concerns. This enables us to show clearly how, in addition to freeriding problems, also asymmetries between countries, in conjunction with multiple externalities can act as an impediment to cooperation, leading to a possible delay or to a failure of cooperation.

Barrett (1997) and Botteon and Carraro (1997) have shown that the freerider effect also destabilizes cooperation when countries exhibit asymmetries. ${ }^{3}$ Barrett (2001), Carraro, Eyckmans, and Finus (2006), and Harstad (2007), however, point out that with asymmetric countries side-payments can play an important role for stabilizing cooperation. Based on information

\footnotetext{
${ }^{3}$ See also Kolstad (2010), Hannesson (2010), and McGinty (2007).
} 
collected in Barrett (2003), Battaglini and Harstad (2012), however, argue that many international environmental agreements either do not include transfers, or include transfers that are "insignificant (at least compared to the size of the problems they are supposed to solve)" (ADD THE EXPLICIT REFERENCE TO THIS QUOTE HERE!!). Folmer, Mouche, Ragland (1993) offer a number of explanations why significant side-payments are rarely observed in international environmental agreements. In line with these results that explicit side-payments are difficult to implement and enforce in practise, we rule them out in our analysis.

Timing aspects of environmental regulation are considered also by Requate (2005), who analyzes the adoption of a new technology in a model with endogenous R\&D but abstracts from problems related with transboundary pollution. Heal and Tarui (2010) endogenize R\&D and abatement efforts in a model with $N$ countries (or 'agents'), where environmental damages depend on the aggregate of emissions. Golombek and Hoel (2004) analyze a two-country model with endogenous R\&D and abatement choices, and R\&D spillovers, but do not consider environmental cooperation.

(THE FORMER SUBSEQUENT TEXT CONCERNING R\&H 2008 I FOUND SOMEWHAT CLUMSY BECAUSE IT BASICALLY SUGGESTED THAT ALL OUR IMPORTANT RESULTS ARE ALREADY IN G\&H AND THE READER WOULD THEN WONDER WHY TO READ OUR PAPER!!!) Our paper is more closely related to Golombek and Hoel (2008) who, similar to us, analyze a two-country model with cooperation in abatement but not in R\&D. In contrast to our paper, the authors consider only the case where abatement obligations are determined in a stage prior to the R\&D stage. The authors identify the 'complementarity effect' that countries may agree on higher abatement targets in order to trigger additional knowledge spillovers, but since they do not consider possible delays in cooperation, they do not obtain result XYZ (PLEASE FILL IN HERE THE MAIN DIFFERENCES TO US). ${ }^{4}$

In a model with an exogenous delay in climate cooperation and bargaining, Beccherle and Tirole (2011) identify an "intertemporal substitution effect" and a "brinkmanship effect" that induce countries to strategically lower their R\&D investments (or other efforts) at the early stage, in order to affect their own (respectively, their competitor's) outside option in the bargaining stage (see also Buchholz and Konrad, 1994, for a related contribution). These authors show that, under such circumstances, total welfare may be even lower than in the absence of any cooperation. In contrast, we abstract from bargaining in our model and instead follow the

\footnotetext{
${ }^{4}$ Environmental policy design in the presence of innovation externalities is also analyzed by Fischer, Parry, Pizer (2003), and Gerlagh, Kverndokk, Rosendahl (2009). Evidence on the importance of technology spillovers is provided, e.g., by Eaton and Kortum (1999). See also Jaffe, Newell, Stavins (2005).
} 
modeling approach that whenever countries cooperate, they succeed in maximizing their joint welfare (REFERENCES HERE OF PAPERS THAT DO THIS). Moreover, we do not assume that there is an exogenous delay in cooperation. If there is a delay, it arises endogenously because it is in the interest of one of the countries.

Harstad (2012) analyzes a model where countries repeatedly invest (e.g., in capacities for renewable engergies), and cooperate in their abatement choices. If a country invests more (e.g., in renewable energies or $R \& D$ ) then it is expected to emit less in the future. As a response, the other countries raise their emissions and lower their investments because the overall damages are quadratic in the pollution stock. The resulting hold-up problem is particularly severe under short-term cooperation, so that the overall outcome can be worse than under no cooperation. Also in our model, a hold-up problem arises under short-term (late) cooperation. If a country invests more in R\&D at the early stage, then it will be asked to abate more in the future. Under delayed cooperation, countries thus strategically lower their R\&D efforts. (THIS DESCRIPTION OF HARSTAD 2012 IS MUCH TOO LONG AND DOES NOT CLEARLY POINT OUT THE DIFFERENCE TO OUR WORK. CAN YOU SHORTEN IT AND MAKE EXPLICIT THE DIFFERENCE TO US?) Battaglini and Harstad (2013) endogenize participation in international environmental agreements in a dynamic setting. The authors show that countries' inability to include investments in a climate contract may actually raise the efficiency of the agreements, because this mitigates the freerider incentive. Since this stabilizing effect depends on an infinite time horizon, it does not obtain in our model, where the dynamic game is finite. In contrast, we allow a more general specification of the spillovers between countries, and focuses explicitly on the role of asymmetries between countries for the timing of cooperation. Finally, Barrett (2006) analyzes the development of 'breakthrough technologies', assuming that countries can sign multiple treaties, one for the development of new technologies, and another one for their deployment. In contrast and as motivated above, we study delays in cooperation when countries cannot cooperate in their production technologies.

The remainder of this paper is organized as follows. Section 2 introduces the basic model. In Section 3, we derive optimality conditions to characterize the outcome in the four different cooperation regimes that we consider: full cooperation, no cooperation, early, and late cooperation. In Section 4, we endogenize the timing of cooperation and identify the effects of different kinds of asymmetries. In Section 5, we introduce a specification of our general model that is suitable especially for an application to climate agreements. Finally, Section 6 concludes. The Appendix collects all formal proofs. 


\section{Basic Model}

Consider two countries $i \in\{1,2\}$ that choose emissions targets. The targets are measured in terms of abatement of emissions relative to some "business-as-usual" scenario. The abatement targets are denoted by $a_{i} \geq 0$. In addition, each country has the possibility to invest in $\mathrm{R} \& \mathrm{D}$ in order to reduce the costs of abatement. ${ }^{5}$ Country $i$ 's R\&D effort is denoted by $r_{i} \geq 0$. Due to environmental externalities, country $i$ 's welfare may depend on overall abatement levels. Furthermore, country i's costs of abatement can, due to knowledge spillovers, depend also on the other country's R\&D effort. More specifically, country $i$ 's welfare, which reflects the net benefit of abatement, is denoted by $\Pi_{i}$ and given by

$$
\Pi_{i}\left(a_{1}, a_{2}, r_{1}, r_{2}\right) \equiv B_{i}\left(a_{1}, a_{2}\right)-C_{i}\left(a_{i}, r_{1}, r_{2}\right)
$$

where $B_{i}$ measures environmental benefits and $C_{i}$ the abatement costs of country $i$, including its R\&D investment costs. In the absence of R\&D spillovers, $C_{i}$ depends on $r_{i}$ but not on $r_{-i}{ }^{6}$ In line with Beccherle and Tirole (2011), we concentrate on linear benefit functions:

$$
B_{i}\left(a_{i}, a_{-i}\right)=b_{i} a_{i}+\beta_{-i} a_{-i}
$$

where $b_{i}>0$ and $\beta_{-i} \in\left[0, b_{i}\right]$. We say that country $-i$ has a positive abatement externality on country $i$ if $\beta_{-i}>0$. In the extreme $\beta_{-i}=b_{i}$, so that country $-i$ 's abatement has the same marginal effect on country $i$ 's total benefit as country $i$ 's own abatement $a_{i}$. The linear specification allows us to show that direct interactions between abatement and R\&D externalities can already lead to strategic delays in cooperation. ${ }^{7}$

We consider general cost functions $C_{i}$ that are convex in $\left(a_{i}, r_{1}, r_{2}\right)$, so that the country's welfare function $\Pi_{i}$ is concave in $\left(a_{1}, a_{2}, r_{1}, r_{2}\right)$. More specifically, we assume that for any $a_{1}$, $a_{2}, r_{1}, r_{2}>0$, cost functions satisfy

$$
\frac{\partial C_{i}}{\partial a_{i}}>0, \frac{\partial^{2} C_{i}}{\partial a_{i}^{2}}>0, \frac{\partial^{2} C_{i}}{\partial r_{i}^{2}}>0, \frac{\partial^{2} C_{i}}{\partial a_{i} \partial r_{i}}<0, \frac{\partial C_{-i}}{\partial r_{i}} \leq 0, \frac{\partial^{2} C_{-i}}{\partial r_{i}^{2}} \geq 0, \frac{\partial^{2} C_{-i}}{\partial r_{-i} \partial r_{i}} \geq 0, \frac{\partial^{2} C_{-i}}{\partial a_{-i} \partial r_{i}} \leq 0 .
$$

\footnotetext{
${ }^{5}$ Hence, we model each country as picking R\&D effort directly. Alternatively, we could assume that R\&D is carried out by firms, but countries can regulate the firms' R\&D efforts indirectly with a subsidy (See for instance Golombek and Hoel 2008). These two modeling approaches are formally equivalent when, as is the case in our framework, there is full information and the subsidy targets directly the firms' R\&D efforts but not the firms' other choices (such as output or prices).

${ }^{6}$ For the indices, by convention, let $-i \equiv 2$ if $i=1$, and $-i \equiv 1$ if $i=2$.

${ }^{7}$ Concave benefit functions exhibit $\partial^{2} B\left(a_{1}, a_{2}\right) /\left(\partial a_{1} \partial a_{2}\right)<0$, which gives rise to what is known as the "raising rivals' costs effect" in industrial organization. This effect renders the analysis less tractable, while it actually "magnifies the strategic incentive" (Beccherle and Tirole, 2011) of delay.
} 
We say that country $i$ exerts a positive $R \mathscr{E} D$ externality on country $-i$ if $\partial C_{-i} / \partial r_{i}<0$. Furthermore, we assume that the cost function $C_{i}$ is U-shaped in $r_{i}$ (for any given values of $a_{i}$ and $r_{-i}$ ), so that there exists a unique cost-minimizing level of $r_{i}{ }^{8}$ The intuition behind the other conditions is also straightforward. The condition $\partial^{2} C_{-i} / \partial r_{-i} \partial r_{i} \geq 0$ for instance captures the standard assumption that R\&D efforts are strategic substitutes. The condition $\partial^{2} C_{i} / \partial a_{i} \partial r_{i}<0$ implies that $\mathrm{R} \& \mathrm{D}$ reduces the marginal cost of abatement. Furthermore, we focus on the natural case where the $\mathrm{R} \& \mathrm{D}$ externalities do not exceed their corresponding direct effects. That is, we assume: $\partial^{2} C_{i} / \partial r_{i}^{2}>\partial^{2} C_{i} / \partial r_{i} \partial r_{-i}$, and $\left|\partial^{2} C_{i} / \partial a_{i} \partial r_{i}\right| \geq\left|\partial^{2} C_{i} / \partial a_{i} \partial r_{-i}\right| .^{9}$

Focusing on the ongoing discussion of climate agreements, we consider countries that have the possibility to cooperate in abatement efforts, but not in R\&D (see Beccherle and Tirole, 2011; Golombek and Hoel, 2008; Harstad, 2012). We also follow the literature (e.g. Barrett, 2001; Kolstad, 2010) by assuming that if countries agree to cooperate, then the abatement targets are always chosen to maximize the total welfare of both countries: $\Pi \equiv \Pi_{1}+\Pi_{2}$. We thereby also abstract from any enforceability issues concerning these agreements. To capture the difficulty of implementing conditional side-payments in practice, we rule out such side-payments altogether. We say that a country has an incentive to cooperate, if its payoff from cooperation exceeds its payoff without cooperation. If both counties have an incentive to cooperate, then cooperation succeeds. In other words, cooperation fails as soon as one country does not have an incentive to cooperate. This can occur when countries are asymmetric, because the benefits of cooperation are, then, also shared asymmetrically. In the case of global climate agreements these asymmetries are substantial. Hence, we are especially interested in identifying the role of asymmetries as an impediment to achieving cooperation.

To understand how the presence of multiple externalities and the timing of cooperation affect outcomes, our approach is to first analyze the following sub-cases independently:

1. Full cooperation: Countries choose $\left(a_{1}^{f}, a_{2}^{f}, r_{1}^{f}, r_{2}^{f}\right)$ cooperatively to maximize the joint surplus $\Pi$.

2. No cooperation: Countries first choose R\&D levels $\left(r_{1}^{n}, r_{2}^{n}\right)$ non-cooperatively, and subsequently choose the abatement levels $\left(a_{1}^{n}, a_{2}^{n}\right)$ also non-cooperatively.

3. Early cooperation: Countries first commit to long-term cooperative abatement levels $\left(a_{1}^{e}, a_{2}^{e}\right)$ and subsequently choose $\mathrm{R} \& \mathrm{D}$ levels $\left(r_{1}^{e}, r_{2}^{e}\right)$ non-cooperatively.

\footnotetext{
${ }^{8}$ Recall that in our formulation, investment costs in R\&D are included in $C_{i}$ as well as the abatement costs.

${ }^{9}$ The latter condition holds with equality if knowledge is treated as a pure public good.
} 
4. Late cooperation: Countries first choose R\&D levels $\left(r_{1}^{l}, r_{2}^{l}\right)$ non-cooperatively and then choose short-term abatement levels $\left(a_{1}^{l}, a_{2}^{l}\right)$ cooperatively.

The first two cases represent benchmarks which we use in order to evaluate the outcomes under early and late cooperation. Overall, the analysis of these cases enables us to identify and to classify the interactions of the different spillover effects under different, exogenously-given timing regimes.

In a second step, we then study the cooperation and timing decision by considering an overall game where the choice whether to cooperate early, late, or not arises endogenously and is part of the equilibrium outcome. The following figure illustrates the time structure of this overall game: ${ }^{10}$

\section{Figure 1}

In the first stage, countries simultaneously decide whether they are willing to sign a longterm agreement or not. Hence, each country $i$ has a binary decision $e_{i}$, where $e_{i}=1$ indicates country $i$ 's willingness to cooperate early, and $e_{i}=0$ means that country $i$ rejects early cooperation. Early cooperation succeeds if and only if $e_{1}=e_{2}=1$. In this case, the subgame "E" is entered, which coincides with the early cooperation case introduced above. Hence, in this subgame, countries first choose their abatement targets cooperatively. Subsequently, they decide about their R\&D investments non-cooperatively.

As soon as some country $i$ blocks long-term cooperation by choosing $e_{i}=0$, early cooperation fails and the countries enter the subgame "LN". In this subgame, countries first choose their R\&D efforts $\left(r_{1}, r_{2}\right)$ simultaneously and non-cooperatively. Subsequently, given $r_{1}$ and $r_{2}$, countries simultaneously decide about the formation of a late (short-term) climate agreement. Hence, at this later cooperation stage each country has again a binary decision $l_{i}$, where $l_{i}=1$ indicates country $i$ 's willingness to cooperate. Late cooperation succeeds if and only if $l_{1}=l_{2}=1$. In this case, countries choose their abatement targets $a_{i}$ cooperatively. Otherwise, $a_{1}$ and $a_{2}$ are determined non-cooperatively. Underlying this sequence of events is the notion that $R \& D$ is a time-consuming process, so current $R \& D$ efforts reduce future abatement costs. ${ }^{11}$

\footnotetext{
${ }^{10}$ The dotted line at the bottom left of the figure indicates that the implementation of the chosen abatement levels under early cooperation is not a decision.

${ }^{11}$ Near-term abatement (before R\&D levels are chosen) is not explicitly modeled. Underlying this approach is the implicit assumption that near-term abatement efforts do not interact strongly with the variables of the model. See Beccherle and Tirole (2011).
} 
Note, that the subgame LN comprises both the late cooperation and the no cooperation case introduced earlier. This implies that at the R\&D stage, countries anticipate whether late cooperation will succeed or fail, and adjust their R\&D efforts accordingly as different strategic effects arise in these cases. We explicitly analyze these strategic effects in Section 3, where the success and the timing (the 'mode') of cooperation is treated as exogenous. When the mode of cooperation is endogenous, then in case of a failure of early cooperation, countries take into account how their R\&D efforts affect also the success of late cooperation. ${ }^{12}$ In Section 4 , we endogenize the mode of cooperation, taking these strategic considerations into account.

\section{Strategic Effects}

In this section, we identify the different strategic effects that arise under early, late, and no cooperation by contrasting the equilibrium conditions for each of the four cases: 1 . full cooperation, 2. no cooperation, 3. early cooperation, and 4. late cooperation. We also use these equilibrium conditions to characterize inefficiencies that arise in the absence of full cooperation, and to obtain comparative welfare results.

\subsection{Full cooperation}

Under full cooperation, countries maximize the joint surplus $\Pi$. Hence, they solve the following maximization problem: $\max _{a_{1}, a_{2}, r_{1}, r_{2}} \Pi\left(a_{1}, a_{2}, r_{1}, r_{2}\right)$. Because the target function is concave, the cooperative solution $\left(a_{1}^{f}, a_{2}^{f}, r_{1}^{f}, r_{2}^{f}\right)$ satisfies the first-order conditions ${ }^{13}$

$$
\begin{aligned}
& \frac{\partial C_{i}}{\partial a_{i}}=b_{i}+\beta_{i} ; \\
& \frac{\partial C_{i}}{\partial r_{i}}+\frac{\partial C_{-i}}{\partial r_{i}}=0 .
\end{aligned}
$$

These optimality conditions are intuitive. The first condition states that country $i$ 's marginal abatement cost equals its aggregated marginal benefit of abatement. The second condition says that the aggregated abatement costs are minimized over $r_{i}$. Both abatement and R\&D spillovers are fully internalized. Due to the convexity of $C_{i}$, expression (2) indicates that the presence of a larger abatement externality $\left(\beta_{i}>0\right)$ implies more abatement. Similarly, expression (3) shows that larger knowledge spillovers from $\mathrm{R} \& \mathrm{D}\left(\partial C_{-i} / \partial r_{i}<0\right)$ imply higher levels of $\mathrm{R} \& \mathrm{D}$.

\footnotetext{
${ }^{12}$ E.g., country 1 may raise its $R \& D$ effort in the subgame $L N$ in order to induce country 2 to agree to the formation of a late coalition.

${ }^{13}$ To increase readability, we suppress the functional arguments and the condition $i \in\{1,2\}$ whenever this does not lead to confusion.
} 


\subsection{No cooperation}

Under no cooperation, countries play a non-cooperative, sequential game. In the first stage, they simultaneously choose their R\&D efforts. In the second stage, they choose their abatement levels. We derive the subgame perfect equilibrium of this game by backwards induction.

In the second stage, R\&D levels $\left(\bar{r}_{1}, \bar{r}_{2}\right)$ are given and country $i$ 's reaction function follows from maximizing its payoff $\Pi_{i}\left(a_{1}, a_{2}, \bar{r}_{1}, \bar{r}_{2}\right)$ w.r.t. $a_{i}$. First-order conditions are

$$
\frac{\partial C_{i}}{\partial a_{i}}=b_{i}
$$

Since the equilibrium in stage 2 depends on $\left(r_{1}, r_{2}\right)$, we write $\left(a_{1}^{n}\left(r_{1}, r_{2}\right), a_{2}^{n}\left(r_{1}, r_{2}\right)\right)$.

In the first stage, countries choose their R\&D levels $\left(r_{1}, r_{2}\right)$ while anticipating the outcome in the second stage. Hence, each country expects the payoff

$$
\Pi_{i}\left(a_{1}^{n}\left(r_{1}, r_{2}\right), a_{2}^{n}\left(r_{1}, r_{2}\right), r_{1}, r_{2}\right)
$$

By the Envelope Theorem, the subgame-perfect Nash equilibrium solves the system

$$
\frac{d \Pi_{i}}{d r_{i}}=\frac{\partial \Pi_{i}}{\partial r_{i}}+\frac{\partial \Pi_{i}}{\partial a_{1}} \frac{\partial a_{1}^{n}}{\partial r_{i}}+\frac{\partial \Pi_{i}}{\partial a_{2}} \frac{\partial a_{2}^{n}}{\partial r_{i}}=-\frac{\partial C_{i}}{\partial r_{i}}+\frac{\partial B_{i}}{\partial a_{-i}} \frac{\partial a_{-i}^{n}}{\partial r_{i}}=0 .
$$

To summarize, the subgame perfect equilibrium outcome $\left(a_{1}^{n}, a_{2}^{n}, r_{1}^{n}, r_{2}^{n}\right)$ is characterized by

$$
\begin{aligned}
& \frac{\partial C_{i}}{\partial a_{i}}=b_{i}, \\
& \frac{\partial C_{i}}{\partial r_{i}}=\beta_{-i} \frac{\partial a_{-i}^{n}}{\partial r_{i}} .
\end{aligned}
$$

Condition (4) differs from (2) as countries neglect abatement spillovers, and the left-hand side of (5) differs from (3) as countries neglect R\&D spillovers. This leads to reduced abatement and R\&D efforts under no cooperation, compared to the fully cooperative outcome.

On the right-hand side of (5), we identify as a strategic double spillover effect that raises R\&D incentives. To understand the intuition behind this effect, observe that by raising its R\&D effort $r_{i}$ in stage 1 , the $\mathrm{R} \& \mathrm{D}$ externality will induce the other country to raise its abatement level $a_{-i}$ in stage 2. Because of the spillover in abatement, this benefits the original country and induces it to raise its $R \& D$ levels. We emphasize that this positive effect on R\&D levels occurs only if there are spillovers in both $R \& D$ and abatement. The following lemma confirms formally that this double spillover effect tends to raise R\&D efforts, compared to the case where the effect is neglected in stage $1 .{ }^{14}$ Hence, it mitigates the aforementioned negative effect on R\&D efforts.

\footnotetext{
${ }^{14}$ The outcome would then be defined by the following system: $\partial C_{i} / \partial a_{i}=b_{i}$ and $\partial C_{i} / \partial r_{i}=0$.
} 
Lemma 1 In the presence of abatement and R\&D externalities, the strategic double spillover effect under no cooperation induces higher R\&D efforts if countries are symmetric.

The symmetry assumption is needed because when countries are asymmetric, a strong increase in the R\&D effort of one country can lead to a crowding-out of R\&D by the other country, so that overall, the R\&D effort of the latter country may be lower than in the absence of the strategic effect.

To summarize, there are three reasons why the outcome under no cooperation differs from the outcome under full cooperation: 1 . the neglect of abatement externalities, 2 . the neglect of R\&D externalities, 3. a double spillover effect that raises $R \& D$ incentives. The first two effects are straightforward and, respectively, lower the incentives for abatement and R\&D. The third effect is more subtle and mitigates the second effect. ${ }^{15}$

\subsection{Early cooperation}

Under early cooperation, countries first commit to long-term abatement choices $\left(a_{1}^{e}, a_{2}^{e}\right)$ cooperatively and subsequently choose their R\&D levels $\left(r_{1}^{e}, r_{2}^{e}\right)$ non-cooperatively. In the spirit of subgame perfection, we analyze the cooperative levels $\left(a_{1}^{e}, a_{2}^{e}\right)$ that maximize the joint surplus $\Pi$ under full anticipation of how the countries react to these abatement levels in stage 2 when choosing their R\&D levels non-cooperatively. More specifically, the reaction to abatement levels $\left(\bar{a}_{1}, \bar{a}_{2}\right)$ is a Nash equilibrium in R\&D levels $\left(r_{1}^{e}, r_{2}^{e}\right)$ that solves (for $i=1,2$ )

$$
\frac{\partial \Pi_{i}\left(\bar{a}_{1}, \bar{a}_{2}, r_{1}, r_{2}\right)}{\partial r_{i}}=0
$$

In stage 1 , the cooperation levels $\left(a_{1}^{e}, a_{2}^{e}\right)$ therefore solve

$$
\max _{a_{1}, a_{2}} \Pi\left(a_{1}, a_{2}, r_{1}^{e}\left(a_{1}, a_{2}\right), r_{2}^{e}\left(a_{1}, a_{2}\right)\right) .
$$

By the Envelope Theorem, the first-order conditions yield for $i=1,2$

$$
\frac{\partial \Pi}{\partial a_{i}}+\frac{\partial \Pi_{2}}{\partial r_{1}} \frac{\partial r_{1}^{e}}{\partial a_{i}}+\frac{\partial \Pi_{1}}{\partial r_{2}} \frac{\partial r_{2}^{e}}{\partial a_{i}}=0
$$

To summarize, the equilibrium outcome under early cooperation $\left(a_{1}^{e}, a_{2}^{e}, r_{1}^{e}, r_{2}^{e}\right)$ satisfies the system

$$
\begin{aligned}
& \frac{\partial C_{i}}{\partial a_{i}}+\frac{\partial C_{-i}}{\partial r_{i}} \frac{\partial r_{i}^{e}}{\partial a_{i}}+\frac{\partial C_{i}}{\partial r_{-i}} \frac{\partial r_{-i}^{e}}{\partial a_{i}}=b_{i}+\beta_{i} \\
& \frac{\partial C_{i}}{\partial r_{i}}=0 .
\end{aligned}
$$

\footnotetext{
${ }^{15}$ A similar effect is obtained by Golombek and Hoel (2004).
} 
Condition (8) differs from (3) as countries neglect knowledge spillovers in their choice of R\&D levels. Hence, as in the case with no cooperation, each country minimizes its own abatement costs, given its abatement target assigned in stage 1 .

We next interpret the equilibrium condition (7). In line with condition (2), its right-hand side displays the aggregated marginal benefit of abatement, because in both cases countries cooperate in stage 1 . The left-hand side however shows, next to the marginal abatement cost of country $i$, two strategic effects which are both due to the R\&D externality.

Because of positive $\mathrm{R} \& \mathrm{D}$ spillovers $\left(\partial C_{-i} / \partial r_{i}<0\right)$, the first of these effects tends to raise the abatement target assigned to country $i$ in the cooperative stage. Intuitively, by assigning a higher abatement target to country $i$, additional R\&D investments by this country are triggered in the non-cooperative stage. This leads to spillovers that reduce country - i's abatement costs. Hence, this strategic effect alleviates the inefficiency resulting from knowledge spillovers that are not internalized in stage 2 .

The second strategic effect counterbalances the first strategic effect because, due to the R\&D spillovers $\left(\partial C_{i} / \partial r_{-i}<0\right)$, it reduces abatement levels in the cooperative stage. Intuitively, by assigning a higher abatement target to country $i$, higher $\mathrm{R} \& \mathrm{D}$ investments by this country are triggered. Because R\&D efforts are strategic substitutes, they partially crowd-out R\&D investments by country $-i$. This reduces the positive spillovers from country $-i$ 's R\&D upon country $i$ 's abatement costs. To reduce this negative side effect, $a_{i}$ is reduced in the cooperative stage.

The next lemma shows that the positive strategic effect outweighs the negative strategic effect so that, taken together, they raise total welfare unambiguously, compared to the case where the effects are neglected in stage $1 .^{16}$ Moreover, under symmetry, early cooperation in abatement levels leads to higher R\&D efforts for each country. Hence, even though there is no direct cooperation in $R \& D$, early cooperation in abatement partially offsets the lack of cooperation in $R \& D$. It, in particular, implies that long-term cooperation in abatement does not lead to a crowding-out in R\&D efforts. Under early cooperation, abatement and R\&D act as complements rather than substitutes. Therefore, we refer to the overall strategic effect under early cooperation as complementarity effect.

Lemma 2 In the presence of knowledge spillovers, the overall strategic effect under early cooperation raises aggregate welfare. Furthermore, if countries are symmetric, it induces higher RED efforts at the non-cooperative stage, by assigning to each country a higher abatement target at the cooperative stage.

\footnotetext{
${ }^{16}$ The outcome would then be defined by the following system: $\partial C_{i} / \partial a_{i}=b_{i}+\beta_{i}$ and $\partial C_{i} / \partial r_{i}=0$.
} 
To summarize, we identify three qualitatively different effects by which the outcome under early cooperation differs from the outcome under full cooperation: 1 . the neglect of R\&D externalities; 2. a complementarity effect of abatement that raises R\&D incentives; 3. a crowding-out effect that lowers $R \& D$ incentives, but which does not offset the aforementioned complementarity effect of abatement.

\subsection{Late cooperation}

Under late cooperation, countries first choose their R\&D levels $\left(r_{1}^{l}, r_{2}^{l}\right)$ non-cooperatively and subsequently choose their abatement levels $\left(a_{1}^{l}, a_{2}^{l}\right)$ cooperatively by signing a short-term agreement to maximize the joint surplus $\Pi$. Hence, given R\&D levels $\left(\bar{r}_{1}, \bar{r}_{2}\right)$, the abatement levels $\left(a_{1}^{l}, a_{2}^{l}\right)$ solve

$$
\frac{\partial \Pi}{\partial a_{i}}=0
$$

This yields abatement levels $a_{1}^{l}\left(r_{1}, r_{2}\right)$ and $a_{2}^{l}\left(r_{1}, r_{2}\right)$ as functions of R\&D levels.

In the first stage, countries play a Nash equilibrium in R\&D levels, anticipating the cooperative abatement levels $\left(a_{1}^{l}\left(r_{1}, r_{2}\right), a_{2}^{l}\left(r_{1}, r_{2}\right)\right)$ in stage 2 . Country $i$ 's maximization problem is $\max _{r_{i}} \Pi_{i}\left(a_{1}\left(r_{1}, r_{2}\right), a_{2}\left(r_{1}, r_{2}\right), r_{1}, r_{2}\right)$. This yields the first-order conditions:

$$
\frac{\partial \Pi_{i}}{\partial r_{i}}+\frac{\partial \Pi_{i}}{\partial a_{i}} \frac{\partial a_{i}^{l}}{\partial r_{i}}+\frac{\partial \Pi_{i}}{\partial a_{-i}} \frac{\partial a_{-i}^{l}}{\partial r_{i}}=0 \Leftrightarrow \frac{\partial C_{i}}{\partial r_{i}}=\left[\frac{\partial B_{i}}{\partial a_{i}}-\frac{\partial C_{i}}{\partial a_{i}}\right] \frac{\partial a_{i}^{l}}{\partial r_{i}}+\frac{\partial B_{i}}{\partial a_{-i}} \frac{\partial a_{-i}^{l}}{\partial r_{i}}
$$

Using (9), we can simplify this condition so that we can characterize the solution under late cooperation $\left(a_{1}^{l}, a_{2}^{l}, r_{1}^{l}, r_{2}^{l}\right)$ by the system

$$
\begin{aligned}
& \frac{\partial C_{i}}{\partial a_{i}}=b_{i}+\beta_{i} \\
& \frac{\partial C_{i}}{\partial r_{i}}=\beta_{-i} \frac{\partial a_{-i}^{l}}{\partial r_{i}}-\beta_{i} \frac{\partial a_{i}^{l}}{\partial r_{i}} .
\end{aligned}
$$

Condition (10) coincides with (2) if the fixed R\&D levels $\bar{r}_{1}$ and $\bar{r}_{2}$ are the same. However, condition (11), which determines the R\&D levels, differs from the optimality condition in the fully cooperative case (3). As under early cooperation, countries neglect knowledge spillovers in their choice of R\&D levels. As compared to (3), the optimality condition (11), therefore, lacks the derivative $\partial C_{-i} / \partial r_{i}$ on its left-hand side. On the right-hand side, we observe two strategic effects that depend on the interaction between the abatement and the R\&D externality. The first effect, $\beta_{-i} \partial a_{-i}^{l} / \partial r_{i}$, tends to increase $\mathrm{R} \& \mathrm{D}$ incentives. Intuitively, if country $i$ raises its $\mathrm{R} \& \mathrm{D}$ effort in stage 1 , this induces country $-i$ to abate more in the cooperative stage due to 
knowledge spillovers that reduce its marginal abatement costs. In the presence of abatement externalities, this positively affects country $i$ 's own welfare and, hence, increases its R\&D incentives. In contrast, the second effect, $-\beta_{i} \partial a_{i}^{l} / \partial r_{i}$, lowers $\mathrm{R} \& \mathrm{D}$ incentives. Intuitively, each country has an incentive to enter the cooperative stage with high marginal abatement costs, because this implies that it will be assigned a lower abatement effort. By lowering its own R\&D effort, a country shifts the burden of abatement towards the other country, in an attempt to redistribute the gains from cooperation in its own favor. This redistributive effect reduces countries' R\&D incentives. The next lemma shows that, under symmetric abatement externalities, the two effects work in opposite directions, but the overall effect lowers R\&D incentives, compared to the case where countries neglect strategic effects in stage $1 .{ }^{17}$

Lemma 3 In stage 1 of the late cooperation game, there are two strategic effects. If abatement externalities are symmetric $\left(\beta_{1}=\beta_{2}>0\right)$, they work in opposite directions. The overall effect, however, leads to lower investments in R\&D and, thus, reduces total welfare.

To summarize, we identify three qualitatively different effects by which the outcome under late cooperation differs from the outcome under full cooperation: 1 . the neglect of R\&D externalities; 2. a redistributive effect that lowers $R \& D$ incentives; 3 . a double externality effect that raises $R \& D$ incentives but does not offset the second effect when abatement externalities are not too asymmetric. ${ }^{18}$

\subsection{Comparisons}

In the following, we use our previous findings to obtain comparative welfare results, that are valid when the mode of cooperation (early, late, no) is treated as exogenous.

Proposition 1 Without RED externalities, early cooperation leads to the fully cooperative outcome and, therefore, to a higher aggregate welfare than late cooperation.

To understand this result note that, in the absence of R\&D externalities, there are no potential gains from cooperation in terms of R\&D. Hence, under full cooperation, given the assigned abatement target, each country minimizes its own abatement costs. But this is also achieved under early cooperation.

\footnotetext{
${ }^{17}$ The outcome would then be defined by the following system: $\partial C_{i} / \partial a_{i}=b_{i}+\beta_{i}$ and $\partial C_{i} / \partial r_{i}=0$.

${ }^{18} \mathrm{By}$ continuity, the assumption of symmetric abatement spillovers $\left(\beta_{1}=\beta_{2}\right)$ in Lemma 3 can be replaced by the requirement that abatement externalities are not too asymmetric.
} 
Proposition 2 Without abatement externalities, the outcome under late cooperation coincides with the outcome under no cooperation so that early cooperation is welfare superior to late cooperation.

In the absence of abatement externalities, there are for any fixed $\mathrm{R} \& \mathrm{D}$ levels no potential gains from cooperation. Hence, late cooperation has no effect upon the final outcome when compared to no cooperation. Early cooperation, however, can achieve welfare gains because, by assigning higher abatement targets to each country in stage 1, countries can trigger additional R\&D spillovers in stage 2 and, thus, partially correct for the market failure induced by the R\&D externality.

Proposition 3 If abatement externalities are symmetric, early cooperation is welfare superior to late cooperation under RED externalities.

Proposition 3 extends the results from Propositions 1 and 2 to situations where there exist both abatement and R\&D externalities. At first sight, one may think that early cooperation should always dominate late cooperation in terms of aggregate welfare. Yet, the proposition has the qualifier that abatement externalities are symmetric. This begs the question whether we can actually dispense with this qualifier. Clearly, by continuity, the proposition will hold also for small asymmetries, but we next show that under large asymmetries early cooperation can sometimes yield a lower aggregate welfare than late cooperation.

To this end, consider an example with extreme asymmetries in abatement and R\&D externalities. Suppose, country 1 benefits only from abatement by country 2, whereas country 2 does not benefit from any abatement at all: $B_{1}\left(a_{1}, a_{2}\right)=a_{2}$ and $B_{2}\left(a_{1}, a_{2}\right)=0\left(b_{1}=b_{2}=\beta_{1}=0\right.$, $\beta_{2}=1$ ). Moreover, suppose country 1 does not benefit from R\&D spillovers, while country 2 benefits only from the R\&D spillovers from country 1 and not from its own R\&D effort: $C_{1}\left(a_{1}, r_{1}, r_{2}\right)=r_{1}^{2}+a_{1}^{2}$ and $C_{2}\left(a_{2}, r_{1}, r_{2}\right)=a_{2}^{3} /\left(1+2 r_{1}\right)+r_{2}^{2}$. Therefore, country 1's optimal abatement is always: $a_{1}=0$. Similarly, R\&D of country 2 induces only costs. Hence: $r_{2}=0$. Using $a_{1}=r_{2}=0$, the payoff functions of the two countries simplify to: $\Pi_{1}=a_{2}-r_{1}^{2}$ and $\Pi_{2}=-a_{2}^{3} /\left(1+2 r_{1}\right) \cdot{ }^{19}$ We next show how the abatement level $a_{2}$ and R\&D level $r_{1}$ depend on the timing of cooperation.

Under early cooperation, the abatement levels are fixed at the R\&D stage, and because $\mathrm{R} \& \mathrm{D}$ is only costly to country 1 , it optimally chooses $r_{1}=0$. Given that country 1 exerts no

\footnotetext{
${ }^{19}$ Alternatively, one can reformulate this example by assuming that country 1 benefits also from its own abatement but faces prohibitively high marginal abatement costs (so $a_{1}=0$ is always obtained), while country 2 faces prohibitively high marginal $\mathrm{R} \& \mathrm{D} \operatorname{costs}$ (so $r_{2}=0$ always holds). Under these assumptions, the same results are obtained.
} 
R\&D effort, the optimal level of abatement under early cooperation maximizes $a_{2}-a_{2}^{3}$, which yields $a_{2}=\sqrt{3} / 3$. This outcome yields aggregate welfare of approximately 0.38 .

Under late cooperation, the abatement levels are chosen after the R\&D efforts and, in contrast to early cooperation, country 1 now has an incentive to invest in R\&D in order to reduce country 2's costs of abatement and, thereby, trigger a higher abatement level at the cooperative stage. Indeed, given some R\&D effort $r_{1}$, late cooperation leads to $a_{2}=\sqrt{3+6 r_{1}} / 3$. Anticipating how country 2 raises its abatement in response to $R \& D$ from country 1 , it is optimal for country 1 to choose a positive $\mathrm{R} \& \mathrm{D}$ level of $r_{1} \approx 0.42$, resulting in a total welfare of approximately $0.43>0.38$.

The counter-intuitive result that late cooperation outperforms early cooperation is best understood by recalling the different strategic effects. We demonstrated this result in a setup where only the double externality effect under late cooperation is present, whereas the complementarity effect under early cooperation is absent. ${ }^{20}$ As a result, country 1's R\&D effort is zero under early cooperation, whereas the double externality effect assures that incentives for R\&D exist under late cooperation. This leads to a higher aggregate welfare under late than under early cooperation.

Finally, we also point out that there is no unambiguous ranking in total welfare of late cooperation versus no cooperation. Indeed, late cooperation can lead to a lower aggregated welfare than no cooperation. This is the case if the strategic redistributive effect is sufficiently strong so that an incentive exists to enter the cooperative stage with high marginal abatement costs. These higher abatement costs then lead to more distortions than without any cooperation, even though the non-cooperative case implies that neither environmental externalities nor knowledge spillover effects are internalized. Beccherle and Tirole (2011) obtain a similar result in a setup with side-payments.

\section{Endogenous Timing of Cooperation}

In this section, we endogenize the success and timing of cooperation by performing an integrated analysis of the overall cooperation game as illustrated in Figure 1. We are especially interested in understanding the conditions under which early cooperation does not arise as an endogenous

\footnotetext{
${ }^{20}$ Formally, this results from $\partial C_{1} / \partial r_{2}=\partial^{2} C_{1} /\left(\partial r_{1} \partial a_{1}\right)=\partial^{2} C_{1} /\left(\partial r_{1} \partial r_{2}\right)=0$. See (7), and the expressions for $\partial r_{i}^{e} / \partial a_{i}$ and $\partial r_{-i}^{e} / \partial a_{i}$ given in the proof of Lemma 2. Note also that Lemma 3 does not apply here, as the abatement externalities are asymmetric in this example. This explains why the overall strategic effect under late cooperation can induce higher investments in R\&D.
} 
mode of cooperation. We build on our results of the previous section.

It follows immediately from Propositions 1 and 2 that when there is only one type of externality (either abatement or R\&D), and countries are symmetric, then early cooperation is always obtained in equilibrium. Hence, early cooperation may fail due to the presence of multiple externalites and due to asymmetries between countries.

In order to gain a better understanding of why and how the presence of multiple externalites and asymmetries can lead to a failure of early cooperation, we focus in particular on the effects of asymmetries in spillovers. Asymmetric spillovers may arise for different reasons. For instance, countries may be asymmetric with respect to their technological state in that one country is a technological leader, while the other is a follower. In this case, knowledge spillovers will mostly be unidirectional, from the leader to the follower. Similarly, asymmetries in abatement spillovers may exist when some countries are, due to their specific location, particularly vulnerable to climate change, while others are less affected, or when one country attaches a higher value to this problem. ${ }^{21}$ In Subsection 4.1, we consider unilateral externalities as an extreme case of asymmetric spillovers. In Subsection 4.2, we then study more thoroughly the interplay between the multiple externality problem and asymmetries, and analyze when this leads to a delay or a failure of cooperation.

\subsection{Unilateral externalities}

An extreme case of asymmetric spillover effects arises in the presence of unilateral externalities. This means that a given type of spillover affects only one country. In this subsection, we address the stability and the timing of cooperation under such unilateral externalities.

Proposition 4 Cooperation fails entirely when there is only a unilateral abatement but no $R \& D$ externality, or when there is a unilateral R\&D but no abatement externality.

Intuitively, when there is only a unilateral externality in either abatement or R\&D, then the welfare of the country that generates the externality does neither depend on the abatement nor on the R\&D choice of the other country. Therefore, this country can attain its maximum welfare without any cooperation (neither early nor late).

Proposition 5 When there is both a unilateral abatement and a unilateral RED externality, cooperation fails if both externalities affect the same country. If each of the externalities affects a different country, then late cooperation fails, while early cooperation can succeed.

\footnotetext{
${ }^{21} \mathrm{~A}$ more classical example of such asymmetries would be two countries that share a river, with one country being located upstream and the other one downstream.
} 
Early cooperation can succeed when there are two unilateral externalities that go in opposite directions and both are of comparable strength (otherwise externalities are mostly unidirectional, so that by continuity, Proposition 4 applies). To understand the intuition behind this result, observe that in the absence of an R\&D externality, the country that generates the abatement externality (say, country 1) always rejects to cooperate, because it would be assigned a higher abatement level under cooperation, which reduces its welfare. Conversely, in the absence of an abatement externality, country 2 rejects to cooperate, because it is assigned a higher abatement level to induce this country to invest more in R\&D. By continuity, one can find intermediate cases where both effects keep each other in balance so that both countries benefit from early cooperation. Underlying this result is the strategic complementarity effect, that can stabilize early cooperation even in the presence of strong asymmetries.

To see more clearly the different strategic effects that are underlying this result, rewrite the optimality conditions for early cooperation $\left((7)\right.$ and (8)) for this case, using $\beta_{1}>\beta_{2}=0$, $\partial C_{1} / \partial r_{2}<\partial C_{2} / \partial r_{1}=0$, and comparative statics results for stage $2:^{22}$

$$
\frac{\partial C_{i}}{\partial r_{i}}=0, \quad \frac{\partial C_{1}}{\partial a_{1}}=b_{1}+\beta_{1}, \quad \frac{\partial C_{2}}{\partial a_{2}}=b_{2}-\frac{\partial C_{1}}{\partial r_{2}} \frac{\partial r_{2}^{e}}{\partial a_{2}},
$$

where the strategic effect $-\partial C_{1} / \partial r_{2} \cdot \partial r_{2}^{e} / \partial a_{2}$ is positive.

Early cooperation succeeds if both countries achieve a welfare at least as large as under no cooperation. The outcome under no cooperation is characterized by (using (4) and (5)):

$$
\frac{\partial C_{1}}{\partial r_{1}}=0, \quad \frac{\partial C_{2}}{\partial r_{2}}=\beta_{1} \frac{\partial a_{1}^{n}}{\partial r_{2}}, \quad \frac{\partial C_{i}}{\partial a_{i}}=b_{i} .
$$

First consider the case where $\beta_{1}=0$. The equilibrium conditions (12) and (13), then, simplify further, and differ only in the strategic effect $-\partial C_{1} / \partial r_{2} \cdot \partial r_{2}^{e} / \partial a_{2}$ that is present under early cooperation, but absent under no cooperation. This effect leads to a higher abatement $a_{2}$ in stage 1 in order to trigger a higher R\&D effort $r_{2}$ in stage 2 and, thus, induces additional R\&D spillovers that benefit country 1 . The effect, therefore, raises $\Pi_{1}$ and lowers $\Pi_{2}$ under early cooperation, compared to the no cooperation case. Hence, for $\beta_{1}=0$, we obtain the following relations (see Proposition 4): $\Pi_{1}^{e}>\Pi_{1}^{n}$, and $\Pi_{2}^{e}<\Pi_{2}^{n}$.

Let us now identify additional effects that occur when $\beta_{1}$ is raised (in a comparative statics sense). Conditions (12) reveal the following effects under early cooperation. 1. $a_{1}$ is raised in stage 1 to create additional abatement spillovers that benefit country 2 (direct effect). This lowers $\Pi_{1}$ and raises $\Pi_{2}$, compared to the situation where the effect is neglected. 2. As a result

\footnotetext{
${ }^{22}$ From the proof of Lemma 2, we obtain with $\partial C_{2} / \partial r_{1}=0: \partial r_{1}^{e} / \partial a_{1}=-\frac{\partial^{2} C_{1}}{\partial a_{1} \partial r_{1}} / \frac{\partial^{2} C_{1}}{\partial r_{1}^{2}}>0, \partial r_{2}^{e} / \partial a_{2}=$ $-\frac{\partial^{2} C_{2}}{\partial a_{2} \partial r_{2}} / \frac{\partial^{2} C_{2}}{\partial r_{2}^{2}}>0$, and $\partial r_{1}^{e} / \partial a_{2}=\partial r_{2}^{e} / \partial a_{1}=0$.
} 
of the first effect, $r_{1}$ is raised in stage 2 , which cushions the negative welfare effect upon $\Pi_{1}$ (but does not neutralize it), while $\Pi_{2}$ is not affected. 3 . The abatement $a_{2}$ is raised in stage 1 (as a result of the higher abatement target $a_{1}$ assigned to country 1), in order to induce country 2 to invest more in $R \& D$ in stage 2, which cushions the negative impact on welfare of the first effect, but also does not neutralize it. The third effect reduces $\Pi_{2}$, but does not offset the positive impact on $\Pi_{2}$ of effect $1 .^{23}$ In combination, the three effects raise $\Pi_{2}$ and reduce $\Pi_{1}$.

In contrast, under no cooperation, conditions (13) reveal the following effects that result from an increase in $\beta_{1}$. 1. Country 2 raises its $R \& D$ effort $r_{2}$ in order to induce additional knowledge spillovers for country 1 , that increases its abatement effort in response (from which country 2 benefits). 2 . As a result of the higher R\&D effort $r_{2}$, country 2 also chooses a higher abatement target $a_{2}$ in stage 2 itself. This reduces the welfare cost incurred by this country due to the higher R\&D effort, but leaves country 1's welfare unaffected (due to $\beta_{2}=0$ ). Overall, these effects raise welfare of both countries. ${ }^{24}$

In sum, raising $\beta_{1}$, we find that $\Pi_{1}$ and $\Pi_{2}$ increase under no cooperation, while $\Pi_{1}$ decreases and $\Pi_{2}$ increases under early cooperation. This implies that the inequality $\Pi_{1}^{e}>\Pi_{1}^{n}$ is reversed for sufficiently high values of $\beta_{1}$. Furthermore, also the relation $\Pi_{2}^{e}<\Pi_{2}^{n}$ is reversed. ${ }^{25}$ Whether or not early cooperation can succeed for some values of $\beta_{1}$ (for a given specification of the cost functions), thus, depends on whether the inequality $\Pi_{2}^{e}<\Pi_{2}^{n}$ is reversed first (for lower values of $\beta_{1}$ ), before $\Pi_{1}^{e}>\Pi_{1}^{n}$ is reversed for higher values of $\beta_{1}$. The example with two unilateral externalities introduced at the end of the following subsection illustrates that such an outcome can easily be obtained.

\subsection{Multiple Externalities and Asymmetric Spillovers}

In the remainder of this section, we analyze more generally how asymmetric spillovers affect the endogenous mode of cooperation in the presence of multiple externalities. To this end, we parameterize the strength of the different types of spillovers and show how the endogenous success and the timing of cooperation in the overall game depend on the relative strength of

\footnotetext{
${ }^{23}$ To see this, note that countries could neglect the first effect, in which case also the other two effects vanish.

${ }^{24}$ Note that country 2 could neglect the effect in stage 1, so taking it into account, this country's welfare is higher. Country 1 benefits from the additional knowledge spillovers, because its own choices of $a_{1}$ and $r_{1}$ do not have any impact on country 2 's decisions ( $a_{1}$ enters linearly in $\Pi_{2}$, and $r_{1}$ does not affect $\left.\Pi_{2}\right)$.

${ }^{25}$ To see this, note that for high values of $\beta_{1}$, under early cooperation the direct effect of this externality upon $a_{1}$ becomes very large (which raises $\Pi_{2}^{e}$ ), and dominates the strategic effects under early and no cooperation that occur due to the presence of knowledge spillovers. The situation, thus, resembles the case with only a unilateral externality in abatement (Proposition 4).
} 
externalities between the two countries.

In particular, let the cost function exhibit the following form:

$$
C_{i}\left(a_{i}, r_{i}, r_{-i}\right)=a_{i}^{2}+r_{i}^{2}-\left(1+a_{i}\right) r_{i}-\rho_{-i} r_{-i}
$$

Moreover, let $b_{1}=b_{2}=1$ so that the resulting payoff function of country $i$ is

$$
\Pi_{i}\left(a_{1}, a_{2}, r_{1}, r_{2}\right)=a_{i}-a_{i}^{2}+r_{i}-r_{i}^{2}+a_{i} r_{i}+\beta_{-i} a_{-i}+\rho_{-i} r_{-i}
$$

The parameter $\rho_{-i} \in[0,1]$ measures the R\&D externality of country $-i$ on country $i$. Note that the payoff function is symmetric with respect to $a_{i}$ and $r_{i}$. Hence, the interpretation of these variables as abatement and $R \& D$ is, at this general level, arbitrary. In principle, they could reflect any type of activities that cause externalities. What distinguishes these two variables is only the assumption that countries can cooperate in their choice of $\left(a_{1}, a_{2}\right)$, but not in their choice of $\left(r_{1}, r_{2}\right){ }^{26}$

As an aggregate measure of the externalities caused by country $i$, we define ${ }^{27}$

$$
\varepsilon_{i} \equiv\left(\beta_{i}+\rho_{i}\right)^{2}+2 \beta_{i} \rho_{i}
$$

If country $i$ does not exert an abatement externality $\left(\beta_{i}=0\right)$, it follows that $\varepsilon_{i}=\rho_{i}^{2}$. Conversely, when $\rho_{i}=0$ then $\varepsilon_{i}=\beta_{i}^{2}$.

Lemma 4 Suppose the countries' payoff functions are given by (14). Then aggregate payoffs are ranked as $\Pi^{e} \geq \Pi^{l} \geq \Pi^{n}$. Contrary to this ranking, country i prefers late over early cooperation $\left(\Pi_{i}^{l}>\Pi_{i}^{e}\right)$ iff $\varepsilon_{i}>2 \varepsilon_{-i}$, while it prefers the non-cooperative outcome over late cooperation $\left(\Pi_{i}^{n}>\Pi_{i}^{l}\right)$ iff $\beta_{i}>\sqrt{2} \beta_{-i}$.

The parametrized model yields the unambiguous ranking $\Pi^{f} \geq \Pi^{e} \geq \Pi^{l} \geq \Pi^{n}$. This intuitive ranking obtains, because with the payoffs (14) the strategic double spillover effect that potentially raises $R \& D$ efforts under no cooperation does not exist. ${ }^{28}$ The ranking gives nevertheless a clear framework for illustrating the misalignment between individual and aggregate payoffs. The Lemma shows that such a misalignment arises between early and late cooperation if there exists a country $i$ whose overall externality $\left(\varepsilon_{i}\right)$ exceeds twice the size of the externality

\footnotetext{
${ }^{26}$ A similar specification is used by Harstad (2012).

${ }^{27}$ This definition is convenient, because welfare often depends on the parameters $\beta_{i}$ and $\rho_{i}$ only via this expression. The interpretation of it as an 'aggregate measure of the externalities' is plausible because the expression depends symmetrically on $\beta_{i}$ and $\rho_{i}$ and is strictly increasing in these parameters.

${ }^{28}$ This is because for the given cost functions $\partial^{2} C_{i} /\left(\partial a_{i} \partial r_{-i}\right)=0$; see the proof of Lemma 1.
} 
caused by the other country $\left(\varepsilon_{-i}\right)$. The Lemma moreover shows that if the abatement externalities do not differ too much $\left(\beta_{1}<\sqrt{2} \beta_{2}\right.$ and $\left.\beta_{2}<\sqrt{2} \beta_{1}\right)$, then both countries still prefer late cooperation to no cooperation. In this case, country $i$ (with $\varepsilon_{i}>2 \varepsilon_{-i}$ ) anticipates that the other country also prefers late to no cooperation. As a result, it will block early cooperation and only an agreement on late cooperation is sustainable.

Lemma 4 compares the payoffs under different, exogenously-given time structures of abatement and R\&D decisions. We can now use these results in order to endogenize the success and the timing of cooperation in the overall game. ${ }^{29}$ To this end, it is convenient to define relative externalities $\left(\varepsilon^{r}\right.$ and $\left.\beta^{r}\right)$ as follows:

$$
\varepsilon^{r} \equiv \frac{\varepsilon_{1}}{\varepsilon_{2}} \quad \text { and } \quad \beta^{r} \equiv \frac{\beta_{1}}{\beta_{2}},
$$

We can now state the main result of this subsection:

Proposition 6 If the payoff functions are given by (14), the endogenous success and timing of cooperation in the overall game depend on the relative externalities $\left(\varepsilon^{r}, \beta^{r}\right)$ as follows:

i) if $\beta^{r} \in(1 / \sqrt{2}, \sqrt{2})$ and $\varepsilon^{r} \in(1 / 2,2)$, then in equilibrium early cooperation succeeds;

ii) if $\beta^{r} \in(1 / \sqrt{2}, \sqrt{2})$ and $\varepsilon^{r} \notin(1 / 2,2)$, then late cooperation takes place;

iii) if $\beta^{r}>\sqrt{2}$ and $\varepsilon^{r}>2$, or $\beta^{r}<1 / \sqrt{2}$ and $\varepsilon^{r}<1 / 2$, cooperation fails entirely;

iv) if $\beta^{r}>\sqrt{2}$ and $\varepsilon^{r}<2$, or $\beta^{r}<1 / \sqrt{2}$ and $\varepsilon^{r}>1 / 2$, either early or no cooperation is obtained in equilibrium, depending on the exact values of $\beta^{r}$ and $\varepsilon^{r} .30$

Figure 2 illustrates these results in a graph. ${ }^{31}$

\section{Figure 2}

\footnotetext{
${ }^{29}$ In general, it is not sufficient to compare welfare in these cases in order to derive the equilibrium outcome of the overall game. The problem is that - if late cooperation is expected to fail for a given set of R\&D strategies $r_{1}$ and $r_{2}$ - then a country may change its R\&D effort in order to induce the other country to agree to cooperate. However, for the given functional forms, this type of strategy is ineffective, as shown in the proof of Proposition 6 .

${ }^{30}$ The original parameter space is 4-dimensional $\left(\beta_{1}, \beta_{2}, \rho_{1}, \rho_{2}\right)$. It is, thus, remarkable that in cases i-iii, the equilibrium outcome depends only on the relative externalities $\varepsilon^{r}$ and $\beta^{r}$. Only in case iv, the equilibrium outcome (early / no cooperation) depends on the full set of parameters. Hence, to determine the combinations of $\varepsilon^{r}$ and $\beta^{r}$ where country 1 (country 2$)$ is indifferent between early and no cooperation under case iv $\left(\Pi_{1}^{e}=\Pi_{1}^{n}\right.$, resp. $\Pi_{2}^{e}=\Pi_{2}^{n}$ ), further parameter restrictions must be imposed. To construct the separating curves in Figure 2 , we assumed $\rho_{2}=1, \beta_{2} \equiv \rho_{1}$, and then eliminated $\rho_{1}$ to obtain two relations $\varepsilon^{r}=\varepsilon^{r}\left(\beta^{r}\right)$, corresponding to $\Pi_{1}^{e}=\Pi_{1}^{n}$, resp. $\Pi_{2}^{e}=\Pi_{2}^{n}$.

${ }^{31}$ By symmetry, it suffices to plot the results for $\beta^{r} \geq 1$. Results for $\beta^{r}<1$ contain no further information.
} 
Figure 2 illustrates that for intermediate values of $\beta^{r}$, where the condition $\beta_{i} \leq \sqrt{2} \beta_{-i}$ is fulfilled for both countries, early cooperation succeeds if the overall externalities $\varepsilon_{i}$ caused by each country $i$ are also not too different (hence, if the condition $\varepsilon_{i} \leq 2 \varepsilon_{-i}$ in Lemma 4 is fulfilled). If the ratio $\varepsilon^{r}$ becomes more extreme, the redistributive effect becomes relevant, and the country that causes the stronger overall externality, prefers to delay cooperation. Hence, late cooperation is obtained in equilibrium. For more extreme values of $\beta^{r}\left(\beta^{r}>\sqrt{2}\right)$, hence, when the abatement externalities caused by the two countries are very different, the country that causes the stronger abatement externality prefers no cooperation to late cooperation. Cooperation then fails entirely, unless there is also a sufficiently strong R\&D externality that works in favor of that country. In this case, the complementarity effect dominates, and both countries prefer early cooperation over the non-cooperative outcome. This explains why in Figure 2, the early cooperation outcome can be obtained also for extreme values of $\beta^{r}$, provided that $\varepsilon^{r}$ is in the relevant range.

To see this latter point more clearly, let us finally apply this specification of our model also to an example with two unilateral externalities. Suppose, country 1 benefits only from R\&D spillovers $\left(\rho_{2}>\beta_{2}=0\right)$, and country 2 benefits only from an abatement externality caused by country $1\left(\beta_{1}>\rho_{1}=0\right)$. This yields (see the proof of Lemma 4 ):

$$
\begin{gathered}
\Pi_{1}^{n}=1+\rho_{2}, \Pi_{2}^{n}=1+\beta_{1} ; \\
\Pi_{1}^{e}=1+\rho_{2}+\frac{1}{6} \rho_{2}^{2}-\frac{1}{3} \beta_{1}^{2}, \Pi_{2}^{e}=1+\beta_{1}+\frac{2}{3} \beta_{1}^{2}-\frac{1}{12} \rho_{2}^{2} ; \\
\Pi_{1}^{l}=1+\rho_{2}-\frac{1}{4} \beta_{1}^{2}, \Pi_{2}^{l}=1+\beta_{1}+\frac{1}{2} \beta_{1}^{2} .
\end{gathered}
$$

Clearly, $\Pi_{1}^{n}>\Pi_{1}^{l}$, so that country 1 always rejects late cooperation. Hence, either early cooperation succeeds, or cooperation fails completely. For early cooperation to succeed, it must hold that $\Pi_{1}^{e} \geq \Pi_{1}^{n}$, which yields the condition $\sqrt{2} \beta_{1} \leq \rho_{2}$. Similarly, the condition $\Pi_{2}^{e} \geq \Pi_{2}^{n}$ yields $\rho_{2} \leq 2 \sqrt{2} \beta_{1}$. Overall, we find that early cooperation succeeds if

$$
\sqrt{2} \beta_{1} \leq \rho_{2} \leq 2 \sqrt{2} \beta_{1}
$$

Hence, as Proposition 5 indicates, given two unilateral externalities that go in opposite directions, early cooperation can succeed (when both externalities are of comparable strength). Otherwise, the country that causes the stronger externality rejects early cooperation. Using our earlier parameter transformation, the range where early cooperation succeeds becomes:

$$
1 / 8 \leq \varepsilon^{r} \leq 1 / 2
$$


while (for $\beta_{2}=\rho_{1} \rightarrow 0$ ) the ratio $\beta^{r}$ converges to infinity. Hence, in Figure 2, this extreme case of two unilateral externalities corresponds to the limit where $\beta^{r} \rightarrow \infty$. Indeed, it can be shown that the separating curves in Figure 2, where country 1 (country 2) is indifferent between early and no cooperation (right-hand side of the Figure), converge to $1 / 2$ resp. $1 / 8$ as $\beta^{r} \rightarrow \infty$.

\section{Application to Global Warming}

In this section, we introduce a specification of benefit and cost functions that is suitable especially for an application of the model to the issue of global warming.

Because the damages of global warming do not depend on where the greenhouse gases are emitted, we set the abatement externality equal to the marginal benefit parameter of the country affected by the externality: $\beta_{i}=b_{-i}$. Hence, the benefits of abatement for each country depend only on the aggregate level of abatement: $a \equiv a_{1}+a_{2}$. Furthermore, we assume that also $\mathrm{R} \& \mathrm{D}$ is a pure public good, highlighting the problem of knowledge spillovers across countries (e.g. Jaffe et al. 2005). In particular, we use the following cost function:

$$
C_{i}\left(a_{i}, r_{i}, r_{-i}\right)=\frac{a_{i}^{2}}{r}+\gamma r_{i}^{2}
$$

where $r \equiv r_{1}+r_{2}$. Under this specification, country $i$ 's investment cost in R\&D is a quadratic function of $r_{i}$. Similarly, the abatement cost is quadratic in $a_{i}$, and declining in the aggregate level of R\&D.

The asymmetry we consider is one where countries differ in their appreciation of abatement. In particular, we assume $b_{1}=b+\delta$ and $b_{2}=b-\delta$, where $b>0$ and $\delta \geq 0$. This yields for the countries' payoff functions:

$$
\Pi_{1}\left(a_{1}, a_{2}, r_{1}, r_{2}\right)=(b+\delta) a-\frac{a_{1}^{2}}{r}-\gamma r_{1}^{2} \quad \text { and } \quad \Pi_{2}\left(a_{1}, a_{2}, r_{1}, r_{2}\right)=(b-\delta) a-\frac{a_{2}^{2}}{r}-\gamma r_{2}^{2},
$$

where $\delta \in[0, b / 2]$ assures an interior solution. If $\delta>0$, country 1 values abatement more than country 2. Note, however, that the aggregated benefit $B_{1}(a)+B_{2}(a)$ is always $2 b a$. This property allows us to derive closed-form solutions for all cases (see the proof of Lemma 5).

Lemma 5 Suppose countries' payoff functions are given by (15). Then aggregate payoffs are ranked as $\Pi^{e} \geq \Pi^{l} \geq \Pi^{n}$. Contrary to this ranking, there exists a critical value $\delta_{1}(b)>0$ such that country 2 prefers late over early cooperation $\left(\Pi_{2}^{l}>\Pi_{2}^{e}\right)$ iff $\delta>\delta_{1}(b)$. Furthermore, there exists a critical value $\delta_{2}(b)>\delta_{1}(b)$ such that in the subgame $L N$, country 2 vetoes late cooperation iff $\delta>\delta_{2}(b)$, because $\Pi_{2}^{n}\left(r_{1}, r_{2}\right)>\Pi_{2}^{l}\left(r_{1}, r_{2}\right)$ then holds for any given R\&D levels. 
Note, that the Lemma implies that in the subgame LN, late cooperation may fail even if both countries prefer the late cooperation to the no cooperation outcome, when the R\&D efforts are determined endogenously in both cases. The problem is that when $\delta>\delta_{2}(b)$, both countries realize that for any given $\mathrm{R} \& \mathrm{D}$ levels, late cooperation will fail in the second stage of the subgame LN because country 2 cannot commit to cooperate when countries determine their R\&D efforts. ${ }^{32}$ In anticipation of this, they choose the non-cooperative R\&D levels $\left(r_{1}^{n}, r_{2}^{n}\right)$ in the first stage, which (for $\delta$ close to $\delta_{2}(b)$ ) leaves them both worse off than under late cooperation.

We can now characterize the equilibrium outcome of the overall game.

Proposition 7 If the payoff functions are given by (15), early cooperation succeeds in the overall game iff $\delta<\delta_{1}(b)$. If $\delta \in\left[\delta_{1}(b), \delta_{2}(b)\right]$, late cooperation is obtained in equilibrium. If $\delta>\delta_{2}(b)$, cooperation fails entirely.

The result of Proposition 7 is best understood by considering Figure 3, which shows country 2's payoff under early, late, and no cooperation (for $b=\gamma=1$, using (19), (20), and (21)).

Figure 3

The discontinuity reflects the transition from the late to the no cooperation outcome. The figure illustrates that only when $\delta$ is small, early cooperation succeeds, while late cooperation can be sustained for a considerably larger set of parameter values. Although early cooperation leads to a higher aggregated welfare than late cooperation, country 2 rejects early cooperation already under a small degree of asymmetry. Under early cooperation, equal abatement levels are assigned to both countries (due to the symmetry of the abatement cost functions). Under late cooperation, in contrast, costs can be redistributed between countries via their strategic choice of R\&D levels (redistributive effect). This makes late cooperation sustainable for higher degrees of asymmetry.

\section{Conclusion}

The Tinbergen rule on public policy (e.g., Tinbergen 1952) tells us that in order to implement multiple policy targets, at least one policy tool is required for each target. Applying this rule

\footnotetext{
${ }^{32}$ Also under this specification, the strategy of country $i$ to manipulate its R\&D effort $r_{i}$ to induce country $-i$ to agree to cooperate late when early cooperation has failed, turns out to be ineffective (see the Proof of Lemma 5). This simplifies the characterization of the equilibrium of the overall game (see Proposition 7 ), because it suffices to compare the payoffs under the different, exogenously-given modes of cooperation.
} 
to cooperation, one cannot expect a climate treaty that addresses only abatement targets to attain the first-best outcome in the presence of multiple market failures such as environmental externalities and knowledge spillovers. Going beyond this classical Tinbergen rule, our analysis shows that things can actually be worse: long-term treaties that address only one externality may fail to materialize, even when they have the potential to raise global welfare substantially. We demonstrated this feature in a stylized model of cooperation between two countries and two externalities that act asymmetrically.

A pessimistic insight from our analysis is that even small asymmetries between countries can cause an inefficient delay in cooperation. Due to the redistributive effect, especially early (long-term) cooperation is very vulnerable to asymmetries. The reason for this is that a delay in cooperation can put one of the countries in a strategically favorable position. A country that benefits relatively less from climate protection can, via its strategic choice of R\&D, shift the burden of abatement costs towards the other country. This favors late (short-term) cooperation, and makes it sustainable also for higher degrees of asymmetry.

On a more optimistic note, we identified a positive complementarity effect of early cooperation. If this effect is dominant, even strong asymmetries do not necessarily destabilize early cooperation. With primarily unilateral externalities, for instance, where one country has (relatively) higher benefits of abatement, while the other country benefits mostly from knowledge spillovers, long-term climate treaties are sustainable. Intuitively, early cooperation requires both countries to adopt more ambitious abatement targets. Therefore, a country with higher benefits of abatement, such as for instance an industrialized country with a relatively high willingness-to-pay for climate stability, may agree to cooperate early in order to induce the other country to abate more as well. Conversely, a country that benefits mostly from knowledge spillovers, such as for instance a developing country with a high potential for abatement, may agree to a long-term abatement target in order to induce the other country to subsequently invest more in R\&D. Such an interdependency in countries' welfare in the presence of multiple market failures facilitates the formation of an early agreement on long-term emission targets.

Our results indicate that the current stalemate in climate negotiations may not necessarily imply that cooperation will fail also in the future. It may simply be a result of strategic delay, with adverse effects upon global welfare. If such a delay is caused by asymmetries between countries, then our results suggest that additional knowledge spillovers might help to reach an earlier and more effective agreement on abatement targets. E.g., countries could try to foster technology transfers, in order to compensate countries that benefit relatively less from 
abatement spillovers for their additional emission reduction efforts. ${ }^{33}$

\footnotetext{
${ }^{33} \mathrm{~A}$ 'Technology Mechanism' was agreed by the 16 'th Conference of the Parties (COP) in Cancun, 2010. "The Technology Mechanism is expected to facilitate the implementation of enhanced action on technology development and transfer in order to support action on mitigation and adaptation to climate change." http://unfccc.int/ttclear/jsp/TechnologyMechanism.jsp, visited 01/13/2013.
} 


\section{Appendix}

This appendix collects the formal proofs of the lemmas and propositions.

Proof of Lemma 1: Due to the convexity of $C_{i}$, it is to show that the right-hand side of (5) is non-negative. In the presence of an abatement externality, we have $\beta_{-i}>0$ so that it remains to be shown that $\partial a_{-i}^{n} / \partial r_{i} \geq 0$. To determine the sign of $\partial a_{-i}^{n} / \partial r_{i}$, we use the firstorder conditions (4) of stage 2 and insert the functions $a_{1}^{n}\left(r_{1}, r_{2}\right)$ and $a_{2}^{n}\left(r_{1}, r_{2}\right)$ that describe the equilibrium outcome:

$$
\frac{\partial C_{i}\left(a_{i}^{n}\left(r_{1}, r_{2}\right), r_{1}, r_{2}\right)}{\partial a_{i}}=b_{i}
$$

Applying the Implicit Function Theorem, we obtain (after rearranging):

$$
\frac{\partial a_{-i}^{n}}{\partial r_{i}}=-\left(\frac{\partial^{2} C_{-i}}{\partial a_{-i} \partial r_{i}}\right) /\left(\frac{\partial^{2} C_{-i}}{\partial a_{-i}^{2}}\right) .
$$

Because by assumption $\partial^{2} C_{-i} / \partial a_{-i} \partial r_{i} \leq 0$, the numerator is non-positive, and due to $\partial^{2} C_{i} / \partial a_{i}^{2}>$ 0 the denominator is positive. Hence, $\partial a_{-i}^{n} / \partial r_{i} \geq 0$, which proves that the right-hand side of (5) is non-negative.

Q.E.D.

Proof of Lemma 2: To show that the overall strategic effect in stage 1 of the early cooperation game increases total welfare, note that countries could neglect this effect in the cooperative stage 1 . Hence, the effect raises welfare whenever it affects the final outcome, and (by (7)) it affects the final outcome in the presence of R\&D spillovers.

To show the second claim, note that the functions $r_{1}^{e}\left(a_{1}, a_{2}\right)$ and $r_{2}^{e}\left(a_{1}, a_{2}\right)$ that describe the outcome of $\mathrm{R} \& \mathrm{D}$ competition in stage 2 , are implicitly defined by the system $\partial C_{i}\left(a_{i}, r_{1}^{e}\left(a_{1}, a_{2}\right)\right.$, $\left.r_{2}^{e}\left(a_{1}, a_{2}\right)\right) / \partial r_{i}=0$ for $i=1,2$ (see (8)). Applying the Implicit Function Theorem, we obtain (after rearranging):

$$
\begin{aligned}
& \frac{\partial r_{i}^{e}}{\partial a_{i}}=\left(-\frac{\partial^{2} C_{i}}{\partial r_{i} \partial a_{i}} \frac{\partial^{2} C_{-i}}{\partial r_{-i}^{2}}\right) /\left(\frac{\partial^{2} C_{i}}{\partial r_{i}^{2}} \frac{\partial^{2} C_{-i}}{\partial r_{-i}^{2}}-\frac{\partial^{2} C_{i}}{\partial r_{i} \partial r_{-i}} \frac{\partial^{2} C_{-i}}{\partial r_{i} \partial r_{-i}}\right) \\
& \frac{\partial r_{-i}^{e}}{\partial a_{i}}=\left(\frac{\partial^{2} C_{i}}{\partial r_{i} \partial a_{i}} \frac{\partial^{2} C_{-i}}{\partial r_{i} \partial r_{-i}}\right) /\left(\frac{\partial^{2} C_{i}}{\partial r_{i}^{2}} \frac{\partial^{2} C_{-i}}{\partial r_{-i}^{2}}-\frac{\partial^{2} C_{i}}{\partial r_{i} \partial r_{-i}} \frac{\partial^{2} C_{-i}}{\partial r_{i} \partial r_{-i}}\right) .
\end{aligned}
$$

Given the assumptions $\partial^{2} C_{i} / \partial r_{i}^{2}>0, \partial^{2} C_{i} / \partial r_{i} \partial r_{-i} \geq 0$, and $\partial^{2} C_{i} / \partial r_{i}^{2}>\partial^{2} C_{i} / \partial r_{i} \partial r_{-i}$, the denominator is always positive. Using $\partial^{2} C_{i} / \partial a_{i} \partial r_{i}<0$ and $\partial^{2} C_{i} / \partial r_{i} \partial r_{-i} \geq 0$, we find that $\partial r_{i}^{e} / \partial a_{i}>0$ and $\partial r_{-i}^{e} / \partial a_{i} \leq 0$. Using the condition $\partial^{2} C_{i} / \partial r_{i}^{2}>\partial^{2} C_{i} / \partial r_{i} \partial r_{-i}$, we find $\partial r_{i}^{e} / \partial a_{i}>\left|\partial r_{-i}^{e} / \partial a_{i}\right|$. If countries are symmetric, then $\partial C_{-i} / \partial r_{i}=\partial C_{i} / \partial r_{-i}$. The overall 
strategic effect is, then, always negative, which (by (8) and (7)) implies higher abatement and higher R\&D levels than in the absence of the strategic effect.

Proof of Lemma 3: Using $\beta \equiv \beta_{1}=\beta_{2}$ and inserting the function $a_{i}^{l}\left(r_{1}, r_{2}\right)$ into (10) yields

$$
\frac{\partial C_{i}\left(a_{i}^{l}\left(r_{1}, r_{2}\right), r_{1}, r_{2}\right)}{\partial a_{i}}=b_{i}+\beta
$$

Applying the Implicit Function Theorem, we obtain after rearranging:

$$
\frac{\partial a_{i}^{l}}{\partial r_{i}}=-\left(\frac{\partial^{2} C_{i}}{\partial a_{i} \partial r_{i}}\right) /\left(\frac{\partial^{2} C_{i}}{\partial a_{i}^{2}}\right) \quad \text { and } \quad \frac{\partial a_{i}^{l}}{\partial r_{-i}}=-\left(\frac{\partial^{2} C_{i}}{\partial a_{i} \partial r_{-i}}\right) /\left(\frac{\partial^{2} C_{i}}{\partial a_{i}^{2}}\right)
$$

Using the regularity conditions $\partial^{2} C_{i} / \partial a_{i}^{2}>0, \partial^{2} C_{i} / \partial a_{i} \partial r_{i}<0, \partial^{2} C_{i} / \partial a_{i} \partial r_{-i} \leq 0$, and $\left|\partial^{2} C_{i} / \partial a_{i} \partial r_{i}\right| \geq\left|\partial^{2} C_{i} / \partial a_{i} \partial r_{-i}\right|$, we find that $\partial a_{i}^{l} / \partial r_{i}$ is positive and $\partial a_{i}^{l} / \partial r_{-i}$ non-negative, and $\partial a_{i}^{l} / \partial r_{i} \geq \partial a_{i}^{l} / \partial r_{-i}$. Hence, we obtain for the overall strategic effect $\beta\left(\partial a_{-i}^{l} / \partial r_{i}-\partial a_{i}^{l} / \partial r_{i}\right) \leq$ 0 , which (by (11)) implies lower R\&D efforts than in the absence of the strategic effect. The reduction in $R \& D$-levels aggravates the problem of under-investments in $R \& D$ (relative to the full cooperation case) and, therefore, reduces total welfare.

Q.E.D.

Proof of Proposition 1: Without R\&D externalities we have $\partial C_{-i} / \partial r_{i}=0$. Using (2) and (3), the cooperative solution $\left(a_{1}^{f}, a_{2}^{f}, r_{1}^{f}, r_{2}^{f}\right)$ is with $i=1,2$ characterized by

$$
\frac{\partial C_{i}}{\partial a_{i}}=b_{i}+\beta_{i} \quad \text { and } \quad \frac{\partial C_{i}}{\partial r_{i}}=0
$$

According to (8) and (7), early cooperation $\left(a_{1}^{e}, a_{2}^{e}, r_{1}^{e}, r_{2}^{e}\right)$ is characterized by the system

$$
\frac{\partial C_{i}}{\partial r_{i}}=0 \quad \text { and } \quad \frac{\partial C_{i}}{\partial a_{i}}=b_{i}+\beta_{i}
$$

The result follows immediately because the two systems of optimality conditions coincide. Q.E.D.

Proof of Proposition 2: Without abatement externalities we have $\beta_{1}=\beta_{2}=0$. Using (4) and (5), the solution without cooperation, $\left(a_{1}^{n}, a_{2}^{n}, r_{1}^{n}, r_{2}^{n}\right)$, solves for $i=1,2$

$$
\frac{\partial C_{i}}{\partial a_{i}}=b_{i} \quad \text { and } \quad \frac{\partial C_{i}}{\partial r_{i}}=0
$$

Using (10) and (11), we find that the late cooperation outcome $\left(a_{1}^{l}, a_{2}^{l}, r_{1}^{l}, r_{2}^{l}\right)$ is characterized by the same system of optimality conditions. Hence, the outcome without cooperation and with late cooperation are identical. 
Early cooperation satisfies the system (8) and (7), which differs from the other system of equations due to the presence of strategic effects. By ignoring them, in stage 1 countries can assure a total welfare at least as large as under late or no cooperation.

Q.E.D.

Proof of Proposition 3: The outcome under late cooperation is characterized by the system (10) and (11). According the Lemma 3, the overall strategic effect in stage 1 (see (11)) is welfare-reducing if $\beta_{1}=\beta_{2}$. The outcome under early cooperation satisfies the system (8) and (7), which differs from (10) and (11). According to Lemma 2, the overall strategic effect in stage 1 (see (7)) is welfare-enhancing. The claim, thus, follows immediately from Lemma 2 and Lemma 3.

Q.E.D.

Proof of Proposition 4: To show that cooperation in the countries' choices of abatement targets fails when there is a unilateral abatement externality but no R\&D externality, note that the country that generates the abatement externality can achieve its own welfare maximum without any cooperation. Hence, this country can never gain from cooperating.

To show that cooperation fails when there is a unilateral $R \& D$ externality but no abatement externality, note first that by Proposition 2 late cooperation in abatement yields no welfare gains. Furthermore, early cooperation fails, because the country that generates the R\&D externality has no gains from it. It is assigned a higher abatement level in the cooperative stage (stage 1) in order to trigger additional R\&D investments by this country in stage 2 . This reduces the welfare of this country that can achieve its own welfare maximum without any cooperation.

Q.E.D.

Proof of Proposition 5: To show the first claim, note that the country that generates both externalities achieves its individual welfare maximum without any cooperation. Hence, whenever cooperation affects the final outcome, it negatively affects this country's welfare.

To show that late cooperation fails if each of the unilateral externalities affects a different country, note that for fixed R\&D levels, the country that generates the abatement externality suffers from cooperation in stage 2. For any given R\&D levels, it attains its individual welfare maximum when ignoring the abatement externality. Hence, it rejects late cooperation.

To show that early cooperation can succeed if both externalities are of comparable strength and each affects a different country, it suffices to demonstrate that there exists an example where this holds. Such an example is provided at the end of Section 4.2.

Q.E.D. 
Proof of Lemma 4: Straightforward calculations yield the following results:

1. No cooperation:

$$
\begin{gathered}
a_{i}^{n}=1 \text { and } r_{i}^{n}=1 ; \\
\Pi_{i}^{n}=1+\beta_{-i}+\rho_{-i} ; \\
\Pi^{n}=2+\beta_{1}+\beta_{2}+\rho_{1}+\rho_{2} .
\end{gathered}
$$

2. Early cooperation:

$$
\begin{gathered}
a_{i}^{e}=\frac{3+2 \beta_{i}+\rho_{i}}{3} \text { and } r_{i}^{e}=\frac{3+\beta_{i}+\rho_{i} / 2}{3}<r_{i}^{f} ; \\
\Pi_{i}^{e}=1+\beta_{-i}+\rho_{-i}+\frac{\left(2 \beta_{-i}+\rho_{-i}\right)^{2}}{6}-\frac{\left(2 \beta_{i}+\rho_{i}\right)^{2}}{12} ; \\
\Pi^{e}=2+\beta_{1}+\beta_{2}+\rho_{1}+\rho_{2}+\frac{\left(2 \beta_{1}+\rho_{1}\right)^{2}}{12}+\frac{\left(2 \beta_{2}+\rho_{2}\right)^{2}}{12} .
\end{gathered}
$$

3. Late cooperation:

$$
\begin{gathered}
a_{i}^{l}=1+\beta_{i} / 2 \text { and } r_{i}^{l}=1=r_{i}^{n} ; \\
\Pi_{i}^{l}=1+\beta_{-i}+\rho_{-i}+\beta_{-i}^{2} / 2-\beta_{i}^{2} / 4 ; \\
\Pi^{l}=2+\beta_{1}+\beta_{2}+\rho_{1}+\rho_{2}+\beta_{1}^{2} / 4+\beta_{2}^{2} / 4 .
\end{gathered}
$$

A direct comparison yields $\Pi^{e} \geq \Pi^{l} \geq \Pi^{n}$.

Moreover, $\Delta \Pi_{i}^{e l} \equiv \Pi_{i}^{e}-\Pi_{i}^{l}=\left(2 \varepsilon_{-i}-\varepsilon_{i}\right) / 12$ so that $\Pi_{i}^{e}<\Pi_{i}^{l}$ if $\varepsilon_{i}>2 \varepsilon_{-i}$. Furthermore, comparing (16) and (18), we find that $\Delta \Pi_{i}^{l n} \equiv \Pi_{i}^{l}-\Pi_{i}^{n}=\left(2 \beta_{-i}^{2}-\beta_{i}^{2}\right) / 4$ so that country $i$ prefers late cooperation over the non-cooperative outcome if $\beta_{i}<\sqrt{2} \beta_{-i}$. Finally $\Delta \Pi_{i}^{e n} \equiv \Pi_{i}^{e}-\Pi_{i}^{n}=$ $\beta_{i}^{2}\left(2 \beta_{-i}^{2} / \beta_{i}^{2}-1\right) / 4+\varepsilon_{i}\left(2 \varepsilon_{-i} / \varepsilon_{i}-1\right) / 12$.

Q.E.D.

Before we state the proof of Proposition 6, we establish the following useful Lemma:

Lemma 6 If $\Delta \Pi_{i}^{l n}\left(r_{1}, r_{2}\right) \equiv \Pi_{i}^{l}\left(r_{1}, r_{2}\right)-\Pi_{i}^{n}\left(r_{1}, r_{2}\right)$ is independent of $r_{-i}$ for $i=1,2$, then in the subgame $L N$, late cooperation succeeds iff $\Pi_{i}^{l}\left(r_{1}^{l}, r_{2}^{l}\right) \geq \Pi_{i}^{n}\left(r_{1}^{n}, r_{2}^{n}\right)$ for $i=1,2$.

Proof of Lemma 6: If $\Delta \prod_{i}^{l n}\left(r_{1}, r_{2}\right)$ does not depend on $r_{-i}$ for $i=1,2$, then country $i$ 's decision whether to accept or reject the formation of a late coalition $\left(l_{i}\right)$ is independent of $r_{-i}$. Hence, if (for any given $r_{-i}$ ) country $i$ prefers the cooperative outcome given $r_{i}=r_{i}^{l}$ over the non-cooperative outcome obtained under $r_{i}^{n}$, and the same holds true for the other country, 
then late cooperation succeeds, and the choices $\left(r_{1}^{l}, r_{2}^{l}\right)$ are optimal given this expectation. Conversely, if there is at least one country $i$ that (for any given $r_{-i}$ ) prefers the outcome under no cooperation given $r_{i}^{n}$ to the outcome obtained under late cooperation given $r_{i}^{l}$, then this country chooses $r_{i}=r_{i}^{n}$, planning to reject late cooperation, irrespective of the value of $r_{-i}$ chosen by the other country (which is fixed when countries choose $l_{i}$ ). Hence, country $-i$ cannot affect country $i$ 's cooperation decision in the LN-subgame via its own R\&D choice, and in anticipation of the failure of cooperation, countries choose $\left(r_{1}^{n}, r_{2}^{n}\right)$ accordingly. A necessary and sufficient condition for late cooperation to succeed is, thus, that $\Pi_{i}^{l}\left(r_{1}^{l}, r_{2}^{l}\right) \geq \Pi_{i}^{n}\left(r_{1}^{n}, r_{2}^{n}\right)$ holds for $i=1$ and $i=2$.

Q.E.D.

Intuitively, if $r_{i}$ affects country $-i$ 's payoff under late cooperation, $\Pi_{-i}^{l}\left(r_{1}, r_{2}\right)$, in exactly the same way as it affects $\Pi_{-i}^{n}\left(r_{1}, r_{2}\right)$, then a change in $r_{i}$ has no effect upon country $-i$ 's decision whether to enter a late coalition or not. In that case, it suffices to compare the payoffs under the no cooperation case (Section 3.2) with the payoffs in the late cooperation case (Section 3.4) to derive the equilibrium in the subgame LN.

Proof of Proposition 6: By (14), $r_{-i}$ enters linearly in country i's payoff. Therefore, both under late and under no cooperation, country $i$ 's abatement following the R\&D stage, $a_{i}\left(r_{1}, r_{2}\right)$, is independent of $r_{-i}$. It follows immediately that $\Delta \prod_{i}^{l n}\left(r_{1}, r_{2}\right)$ is also independent of $r_{-i}$, so Lemma 6 applies. Hence, to determine the endogenous success and the timing of cooperation in the overall game, it suffices to compare the equilibrium outcomes of the early, late, and no cooperation cases. Now we apply Lemma 4.

If $\beta^{r} \in(\sqrt{2} / 2, \sqrt{2})$ and $\varepsilon^{r} \in(1 / 2,2)$ then it follows from the Lemma that for either country $i \in\{1,2\}$ we have the ordering $\Pi_{i}^{e} \geq \Pi_{i}^{l} \geq \Pi_{i}^{n}$. This leads to the unique equilibrium outcome of early cooperation.

If $\beta^{r} \in(\sqrt{2} / 2, \sqrt{2})$ and $\varepsilon^{r} \notin(1 / 2,2)$ then for either country $i \in\{1,2\}$ it holds $\Pi_{i}^{l}>\Pi_{i}^{n}$, while there exists one country $j$ for which $\Pi_{j}^{e}<\Pi_{j}^{l}$. This leads to the late cooperation outcome.

If $\beta^{r}>\sqrt{2}$ and $\varepsilon^{r}>2$ then $\Pi_{1}^{e}<\Pi_{1}^{l}$ and $\Pi_{1}^{l}<\Pi_{1}^{n}$, and country 1's most preferred outcome is $\Pi_{1}^{n}$. Because country 1 can obtain this outcome by rejecting both early and late cooperation, there is no cooperation in any subgame perfect equilibrium. By symmetry the same holds for $\varepsilon^{r}<1 / 2$ and $\beta^{r}<1 / \sqrt{2}$.

If $\beta^{r}>\sqrt{2}$ and $\varepsilon^{r} \in(1 / 2,2)$ then $\Pi_{2}^{e}>\Pi_{2}^{l}>\Pi_{2}^{n}$, while $\Pi_{1}^{e}>\Pi_{1}^{l}$ and $\Pi_{1}^{l}<\Pi_{1}^{n}$. Hence, country 2's preferred outcome is early cooperation. In the case that $\Pi_{1}^{e}>\Pi_{1}^{n}$, also county 1 's preferred outcome is early cooperation and early cooperation arises in equilibrium. If $\Pi_{1}^{e}<\Pi_{1}^{n}$, county 1's preferred outcome is no cooperation, which it can always reach by rejecting any form 
of cooperation. As a result, the unique equilibrium outcome is no cooperation. In the Proof of Lemma 4 , it is shown that $\Pi_{i}^{e}-\Pi_{i}^{n}=\beta_{i}^{2}\left(2 \beta_{-i}^{2} / \beta_{i}^{2}-1\right) / 4+\varepsilon_{i}\left(2 \varepsilon_{-i} / \varepsilon_{i}-1\right) / 12$ so that the difference is decreasing in $\beta^{r}$. As a result the former case arises for $\beta^{r}>\sqrt{2}$ but sufficiently small (close to $\sqrt{2}$ ), and the latter one for $\beta^{r}$ sufficiently large. By symmetry, the same holds for $\beta^{r}<1 / \sqrt{2}$ and $\varepsilon^{r} \in(1 / 2,2)$. Finally, if $\varepsilon^{r}<1 / 2$ and $\beta^{r}>\sqrt{2}$ then it follows from Lemma 4 that $\Pi_{1}^{e}>\Pi_{1}^{l}, \Pi_{1}^{l}<\Pi_{1}^{n}, \Pi_{2}^{l}>\Pi_{2}^{e}$, and $\Pi_{2}^{l}>\Pi_{2}^{n}$. Again, late cooperation is never obtained as country 1 prefers the non-cooperative over the late cooperation outcome. Hence, either early or no cooperation is obtained in equilibrium.

Q.E.D.

Proof of Lemma 5: Straight-forward calculations yields the following results:

1. No cooperation:

$$
\begin{gathered}
a_{1}^{n}=\frac{(b+\delta)\left(3 b^{2}-\delta^{2}\right)}{8 \gamma}, \quad a_{2}^{n}=\frac{(b-\delta)\left(3 b^{2}-\delta^{2}\right)}{8 \gamma}, \quad r_{1}^{n}=\frac{3 b^{2}+2 b \delta-\delta^{2}}{8 \gamma}, \quad r_{2}^{n}=\frac{3 b^{2}-2 b \delta-\delta^{2}}{8 \gamma} \\
\Pi_{1}^{n}=\frac{27 b^{4}+12 b^{3} \delta-22 b^{2} \delta^{2}-4 b \delta^{3}+3 \delta^{4}}{64 \gamma}, \quad \Pi_{2}^{n}=\frac{27 b^{4}-12 b^{3} \delta-22 b^{2} \delta^{2}+4 b \delta^{3}+3 \delta^{4}}{64 \gamma} ; \quad \text { (19) } \\
\Pi^{n}=\frac{27 b^{4}-22 b^{2} \delta^{2}+3 \delta^{4}}{32 \gamma} .
\end{gathered}
$$

2. Early cooperation: ${ }^{34}$

$$
\begin{gathered}
a_{i}^{e}=\frac{216 b^{3}}{125 \gamma}=1.728 b^{3} / \gamma, \quad r_{i}^{e}=\frac{18 b^{2}}{25 \gamma}=0.72 b^{2} / \gamma \\
\Pi_{1}^{e}=\frac{108 b^{3}(b+4 \delta)}{125 \gamma}=108 \Pi_{1}^{f} / 125, \quad \Pi_{2}^{e}=\frac{108 b^{3}(b-4 \delta)}{125 \gamma}=108 \Pi_{2}^{f} / 125 \\
\Pi^{e}=\frac{216 b^{4}}{125 \gamma}=108 \Pi^{f} / 125 .
\end{gathered}
$$

3. Late cooperation ${ }^{35}$ :

$$
a_{i}^{l}=b^{3} / \gamma, \quad r_{1}^{l}=\frac{b^{2}+2 b \delta}{2 \gamma}, \quad r_{2}^{l}=\frac{b^{2}-2 b \delta}{2 \gamma}
$$

\footnotetext{
${ }^{34}$ In the second stage of the early cooperation subgame, countries minimize their individual costs, given $\left(a_{1}, a_{2}\right)$ determined in the first stage. As a result, reduced cost functions $C_{i}\left(a_{1}, a_{2}\right)$ are obtained that depend only on the abatement levels. The target function in stage 1 is then: $2 b a-C_{1}\left(a_{1}, a_{2}\right)-C_{2}\left(a_{1}, a_{2}\right)$. This is independent of $\delta$. The resulting $\left(a_{1}^{e}, a_{2}^{e}\right)$ are, therefore, identical. This symmetry property simplifies the derivation of the early cooperation outcome.

${ }^{35}$ The parameter restriction $\delta \in[0, b / 2]$ ensures that all non-negativity constraints are automatically satisfied.
} 


$$
\begin{gathered}
\Pi_{1}^{l}=b^{2} \frac{3 b^{2}+4 b \delta-4 \delta^{2}}{4 \gamma}, \quad \Pi_{2}^{l}=b^{2} \frac{3 b^{2}-4 b \delta-4 \delta^{2}}{4 \gamma} \\
\Pi^{l}=b^{2} \frac{3 b^{2}-4 \delta^{2}}{2 \gamma}
\end{gathered}
$$

A direct comparison yields $\Pi^{e} \geq \Pi^{l} \geq \Pi^{n}$.

Given these results, it is straight-forward to verify that in the relevant range, country 2 prefers early over late cooperation $\left(\Pi_{2}^{e} \geq \Pi_{2}^{l}\right)$ iff $\delta \leq \delta_{1}(b) \equiv(307-2 \sqrt{21781}) b / 250 \approx 0.047 b$.

In the subgame LN, for given R\&D levels $\left(r_{1}, r_{2}\right)$, late cooperation succeeds if both countries achieve a higher welfare than in the absence of cooperation, hence, if $\Delta \Pi_{1}^{l n}\left(r_{1}, r_{2}\right) \geq 0$ and $\Delta \Pi_{2}^{l n}\left(r_{1}, r_{2}\right) \geq 0$. Under no cooperation (for fixed R\&D levels $\left(r_{1}, r_{2}\right)$ ), country $i$ 's abatement is determined by condition (4): $\partial C_{i} / \partial a_{i}=b_{i}$. Using $C_{i}=\frac{a_{i}^{2}}{r}+\gamma r_{i}^{2}, b_{1}=b+\delta$, and $b_{2}=b-\delta$, this yields

$$
a_{1}^{n}\left(r_{1}, r_{2}\right)=(b+\delta) r / 2 \quad \text { and } \quad a_{2}^{n}\left(r_{1}, r_{2}\right)=(b-\delta) r / 2,
$$

and, hence: $a=b r$. Countries' payoffs, thus, become:

$$
\Pi_{1}^{n}\left(r_{1}, r_{2}\right)=\left(3 b^{2}+2 b \delta-\delta^{2}\right) r / 4-\gamma r_{1}^{2}, \quad \Pi_{2}^{n}\left(r_{1}, r_{2}\right)=\left(3 b^{2}-2 b \delta-\delta^{2}\right) r / 4-\gamma r_{2}^{2}
$$

Under late cooperation (again for fixed R\&D levels), country $i$ 's abatement is determined by condition (10): $\partial C_{i} / \partial a_{i}=b_{i}+\beta_{i}$. Using $\beta_{i}=b_{-i}$, we, thus, obtain $a_{1}^{l}=a_{2}^{l}=b r$, and $a=2 b r$. This yields the following expressions for welfare:

$$
\Pi_{1}^{l}\left(r_{1}, r_{2}\right)=\left(b^{2}+2 b \delta\right) r-\gamma r_{1}^{2}, \quad \Pi_{2}^{l}\left(r_{1}, r_{2}\right)=\left(b^{2}-2 b \delta\right) r-\gamma r_{2}^{2}
$$

This implies

$$
\Delta \Pi_{1}^{l n}\left(r_{1}, r_{2}\right)=\left(b^{2}+6 b \delta+\delta^{2}\right) r / 4>0 \quad \text { and } \quad \Delta \Pi_{2}^{l n}\left(r_{1}, r_{2}\right)=\left(b^{2}-6 b \delta+\delta^{2}\right) r / 4 .
$$

Hence, for any fixed $\left(r_{1}, r_{2}\right)$, country 1 is always willing to cooperate. Country 2 cooperates if $b^{2}-6 b \delta+\delta^{2} \geq 0$, which, for the relevant interval $\delta \in[0, b / 2]$, yields the critical value $\delta_{2}(b) \equiv b(3-2 \sqrt{2}) \approx 0.17 b$. If $\delta$ is below this value, it holds that $\Delta \Pi_{2}^{\ln }\left(r_{1}, r_{2}\right)>0$. As $\delta_{2}(b)$ is independent of $r_{1}$ and $r_{2}$, late cooperation succeeds in the subgame LN iff $\delta \leq \delta_{2}(b)$. Q.E.D.

Proof of Proposition 7: It is straight-forward to show (using (20) and (21)) that country 1 always prefers the early over the late cooperation outcome. The result, thus, follows immediately from Lemma 5 .

Q.E.D. 


\section{References}

[1] Barrett, S. (1994) Self-enforcing international environmental agreements. Oxford Economic Papers 46, 878-894

[2] Barrett, S. (1997). Heterogeneous international environmental agreements. In C. Carraro (Ed.), International environmental negotiations: Strategic policy issues. Cheltenham: Edward Elgar.

[3] Barrett, S. (2001) International cooperation for sale. European Economic Review 45, 18351850

[4] Barrett, S. (2003) Environment and Statecraft. Oxford University Press.

[5] Barrett, S. (2006) Climate Treaties and "Breakthrough" Technologies. AEA Papers and Proceedings 96, 22-25

[6] Battaglini, M. and B. Harstad (2012) Participation and Duration of Environmental Agreements. NBER Working Paper 18585

[7] Beccherle, J. and J. Tirole (2011) Regional Initiatives and the Cost of Delaying Binding Climate Change Agreements. Journal of Public Economics 95, 1339-1348

[8] Botteon, M. and C. Carraro (1997) Burden sharing and coalition stability in environmental negotiations with asymmetric countries. In C. Carraro (Ed.), International environmental negotiations: Strategic policy issues. Cheltenham: Edward Elgar.

[9] Buchholz, W. and K. Konrad (1994) Global Environmental Problems and the Strategic Choice of Technology. Journal of Economics 60, 299-321

[10] Carraro, C., J. Eyckmans and M. Finus (2006) Optimal transfers and participation decisions in international environmental agreements. Review of International Organizations 1, 379-396

[11] Carraro, C. and D. Siniscalco (1993) Strategies for the international protection of the environment. Journal of Public Economics 52, 309-328

[12] Eaton, J. and S. Kortum (1999) International Technology Diffusion: Theory and Measurement. International Economic Review 40, 537-570 
[13] Finus, M. (2008) Game theoretic research on the design of international environmental agreements: insights, critical remarks, and future challenges. International Review of Environmental and Resource Economics 2, 29-67

[14] Fischer, C., Parry, I.W.H. and W.A. Pizer (2003) Instrument choice for environmental protection when technological innovation is endogenous. Journal of Environmental Economics and Management 45, 523-545

[15] Folmer, H., Mouche, P.v. and S. Ragland (1993) Interconnected Games and International Environmental Problems. Environmental and Resource Economics 3, 313-335

[16] Gerlagh, R., Kverndokk, S. and K.E. Rosendahl (2009) Optimal Timing of Climate Change Policy: Interaction Between Carbon Taxes and Innovation Externalities. Environmental and Resource Economics 43, 369-390

[17] Golombek, R. and M. Hoel (2004) Unilateral Emission Reductions and Cross-Country Technology Spillovers, The B.E. Journal of Economic Analysis 8 Policy, vol. advances 4, issue 2 , article 3

[18] Golombek, R. and M. Hoel (2008) Endogenous technology and tradable emission quotas. Resource and Energy Economics 30, 197-208

[19] Hannesson, B. (2010) The coalition of the willing: Effect of country diversity in an environmental treaty game. Review of International Organizations 5, 461-474

[20] Harstad, B. (2007) Harmonization and Side Payments in Political Cooperation. American Economic Review 97, 871-889

[21] Harstad, B. (2012) The Dynamics of Climate Agreements. mimeo

[22] Heal, G. and N. Tarui (2010) Investment and emission control under technology and pollution externalities. Resource and Energy Economics 32, 1-14

[23] Jaffe, A.B., Newell, R.G. and N. Stavins (2005) A tale of two market failures: Technology and environmental policy. Ecological Economics 54, 164-174

[24] Kolstad, C.D. (2010) Equity, Heterogeneity and International Environmental Agreements. The B.E. Journal of Economic Analysis \& Policy 10, symposium, art. 3

[25] McGinty, M. (2007) International environmental agreements among asymmetric nations. Oxford Economic Papers 59, 45-62 
[26] Requate, T. (2005) Timing and Commitment of Environmental Policy, Adoption of New Technology, and Repercussions on R\&D. Environmental and Resource Economics 31, 175199

[27] Tinbergen, J. (1952) On the Theory of Economic Policy. Amsterdam: North-Holland.

[28] Ulph, A. and D. Ulph (2007) Climate change - environmental and technology policies in a strategic context. Environmental and Resource Economics 37, 159-180 




\section{SFB 649 Discussion Paper Series 2014}

For a complete list of Discussion Papers published by the SFB 649, please visit http://sfb649.wiwi.hu-berlin.de.

001 "Principal Component Analysis in an Asymmetric Norm" by Ngoc Mai Tran, Maria Osipenko and Wolfgang Karl Härdle, January 2014.

002 "A Simultaneous Confidence Corridor for Varying Coefficient Regression with Sparse Functional Data" by Lijie Gu, Li Wang, Wolfgang Karl Härdle and Lijian Yang, January 2014.

003 "An Extended Single Index Model with Missing Response at Random" by Qihua Wang, Tao Zhang, Wolfgang Karl Härdle, January 2014.

004 "Structural Vector Autoregressive Analysis in a Data Rich Environment: A Survey" by Helmut Lütkepohl, January 2014.

005 "Functional stable limit theorems for efficient spectral covolatility estimators" by Randolf Altmeyer and Markus Bibinger, January 2014.

006 "A consistent two-factor model for pricing temperature derivatives" by Andreas Groll, Brenda López-Cabrera and Thilo Meyer-Brandis, January 2014.

007 "Confidence Bands for Impulse Responses: Bonferroni versus Wald" by Helmut Lütkepohl, Anna Staszewska-Bystrova and Peter Winker, January 2014.

008 "Simultaneous Confidence Corridors and Variable Selection for Generalized Additive Models" by Shuzhuan Zheng, Rong Liu, Lijian Yang and Wolfgang Karl Härdle, January 2014.

009 "Structural Vector Autoregressions: Checking Identifying Long-run Restrictions via Heteroskedasticity" by Helmut Lütkepohl and Anton Velinov, January 2014.

010 "Efficient Iterative Maximum Likelihood Estimation of HighParameterized Time Series Models" by Nikolaus Hautsch, Ostap Okhrin and Alexander Ristig, January 2014.

011 "Fiscal Devaluation in a Monetary Union" by Philipp Engler, Giovanni Ganelli, Juha Tervala and Simon Voigts, January 2014.

012 "Nonparametric Estimates for Conditional Quantiles of Time Series" by Jürgen Franke, Peter Mwita and Weining Wang, January 2014.

013 "Product Market Deregulation and Employment Outcomes: Evidence from the German Retail Sector" by Charlotte Senftleben-König, January 2014.

014 "Estimation procedures for exchangeable Marshall copulas with hydrological application" by Fabrizio Durante and Ostap Okhrin, January 2014.

015 "Ladislaus von Bortkiewicz - statistician, economist, and a European intellectual" by Wolfgang Karl Härdle and Annette B. Vogt, February 2014.

016 "An Application of Principal Component Analysis on Multivariate TimeStationary Spatio-Temporal Data" by Stephan Stahlschmidt, Wolfgang Karl Härdle and Helmut Thome, February 2014.

017 "The composition of government spending and the multiplier at the Zero Lower Bound" by Julien Albertini, Arthur Poirier and Jordan RoulleauPasdeloup, February 2014.

018 "Interacting Product and Labor Market Regulation and the Impact of Immigration on Native Wages" by Susanne Prantl and Alexandra SpitzOener, February 2014.

\section{SFB 649, Spandauer Straße 1, D-10178 Berlin http://sfb649.wiwi.hu-berlin.de}

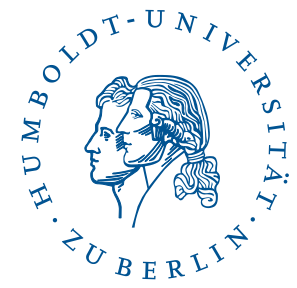




\title{
SFB 649 Discussion Paper Series 2014
}

\author{
For a complete list of Discussion Papers published by the SFB 649, \\ please visit http://sfb649.wiwi.hu-berlin.de.
}

019 "Unemployment benefits extensions at the zero lower bound on nominal interest rate" by Julien Albertini and Arthur Poirier, February 2014.

020 "Modelling spatio-temporal variability of temperature" by Xiaofeng Cao, Ostap Okhrin, Martin Odening and Matthias Ritter, February 2014.

021 "Do Maternal Health Problems Influence Child's Worrying Status? Evidence from British Cohort Study" by Xianhua Dai, Wolfgang Karl Härdle and Keming Yu, February 2014.

022 "Nonparametric Test for a Constant Beta over a Fixed Time Interval" by Markus Reiß, Viktor Todorov and George Tauchen, February 2014.

023 "Inflation Expectations Spillovers between the United States and Euro Area" by Aleksei Netšunajev and Lars Winkelmann, March 2014.

024 "Peer Effects and Students' Self-Control" by Berno Buechel, Lydia Mechtenberg and Julia Petersen, April 2014.

025 "Is there a demand for multi-year crop insurance?" by Maria Osipenko, Zhiwei Shen and Martin Odening, April 2014.

026 "Credit Risk Calibration based on CDS Spreads" by Shih-Kang Chao, Wolfgang Karl Härdle and Hien Pham-Thu, May 2014.

027 "Stale Forward Guidance" by Gunda-Alexandra Detmers and Dieter Nautz, May 2014.

028 "Confidence Corridors for Multivariate Generalized Quantile Regression" by Shih-Kang Chao, Katharina Proksch, Holger Dette and Wolfgang Härdle, May 2014.

029 "Information Risk, Market Stress and Institutional Herding in Financial Markets: New Evidence Through the Lens of a Simulated Model" by Christopher Boortz, Stephanie Kremer, Simon Jurkatis and Dieter Nautz, May 2014.

030 "Forecasting Generalized Quantiles of Electricity Demand: A Functional Data Approach" by Brenda López Cabrera and Franziska Schulz, May 2014.

031 "Structural Vector Autoregressions with Smooth Transition in Variances The Interaction Between U.S. Monetary Policy and the Stock Market" by Helmut Lütkepohl and Aleksei Netsunajev, June 2014.

032 "TEDAS - Tail Event Driven ASset Allocation" by Wolfgang Karl Härdle, Sergey Nasekin, David Lee Kuo Chuen and Phoon Kok Fai, June 2014.

033 "Discount Factor Shocks and Labor Market Dynamics" by Julien Albertini and Arthur Poirier, June 2014.

034 "Risky Linear Approximations" by Alexander Meyer-Gohde, July 2014

035 "Adaptive Order Flow Forecasting with Multiplicative Error Models" by Wolfgang Karl Härdle, Andrija Mihoci and Christopher Hian-Ann Ting, July 2014

036 "Portfolio Decisions and Brain Reactions via the CEAD method" by Piotr Majer, Peter N.C. Mohr, Hauke R. Heekeren and Wolfgang K. Härdle, July 2014

037 "Common price and volatility jumps in noisy high-frequency data" by Markus Bibinger and Lars Winkelmann, July 2014

038 "Spatial Wage Inequality and Technological Change" by Charlotte Senftleben-König and Hanna Wielandt, August 2014

039 "The integration of credit default swap markets in the pre and postsubprime crisis in common stochastic trends" by Cathy Yi-Hsuan Chen, Wolfgang Karl Härdle, Hien Pham-Thu, August 2014

\section{SFB 649, Spandauer Straße 1, D-10178 Berlin http://sfb649.wiwi.hu-berlin.de}

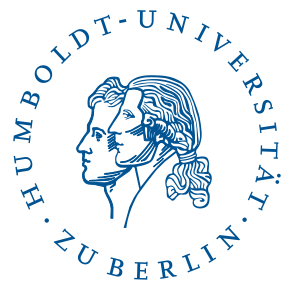




\section{SFB 649 Discussion Paper Series 2014}

For a complete list of Discussion Papers published by the SFB 649, please visit http://sfb649.wiwi.hu-berlin.de.

040 "Localising Forward Intensities for Multiperiod Corporate Default" by Dedy Dwi Prastyo and Wolfgang Karl Härdle, August 2014.

041 "Certification and Market Transparency" by Konrad Stahl and Roland Strausz, September 2014.

042 "Beyond dimension two: A test for higher-order tail risk" by Carsten Bormann, Melanie Schienle and Julia Schaumburg, September 2014.

043 "Semiparametric Estimation with Generated Covariates" by Enno Mammen, Christoph Rothe and Melanie Schienle, September 2014.

044 "On the Timing of Climate Agreements" by Robert C. Schmidt and Roland Strausz,, September 2014. 